\title{
Asymmetric Reference-dependent Reciprocity, Downward Wage Rigidity, and the Employment
}

\author{
Contract*
}

\author{
Alex Dickson and Marco Fongoni ${ }^{\dagger}$ \\ Department of Economics, University of Strathclyde, Glasgow, UK
}

March 22, 2019

\begin{abstract}
We develop a model of asymmetric reciprocity and optimal wage setting based on contractual incompleteness, fairness, and reference dependence and loss aversion in the evaluation of wages by workers. The model establishes a positive wage-effort relationship capturing a worker's 'asymmetric reference-dependent reciprocity', in which loss aversion implies negative reciprocity is stronger than positive reciprocity. Our theory provides an explanation for the observed asymmetry and dynamics of workers' reciprocity and establishes a micro-foundation for downward wage rigidity, the implications of which shed new light on a forward-looking firm's optimal wage setting and hiring decisions.
\end{abstract}

JEL Codes: D91, E70, J30, J41.

Keywords: reference dependence, loss aversion, asymmetric reciprocity, downward wage rigidity.

\footnotetext{
*A previous version of this paper circulated under the title "A Theory of Wage Setting Behaviour".

${ }^{\dagger}$ Corresponding author: e-mail: marco.fongoni@strath.ac.uk.
} 


\section{Introduction}

There is an emerging consensus in the literature that behavioural concerns such as fairness, workers' morale and reciprocity influence firms' wage setting behaviour (Fehr et al., 2009). These aspects are also considered to be the key behavioural forces that underlie the observation of downward wage rigidity: compensation managers may refrain from cutting wages following adverse economic conditions if they believe this will negatively affect workers' morale and effort (Bewley, 2007). Inspired by these ideas, we develop a theory of asymmetric reciprocity and downward wage rigidity based on contractual incompleteness, fairness, and reference dependence and loss aversion in the evaluation of wage contracts by workers.

The theory sheds light on the sources of asymmetry and dynamics of workers' reciprocity documented by the empirical literature; and on its implications for optimal wage setting and the employment contract. In particular, the paper makes the following contributions: i) it offers a psychological foundation - based on loss aversion and reference wage adaptation - for the observed asymmetry, and temporary nature of, workers' reciprocity; ii) it provides a transparent, and plausible, theoretical micro-foundation for dynamic downward wage rigidity; and iii) it sheds new light on the implications of 'asymmetric referencedependent reciprocity' and wage rigidity for a forward-looking firm's optimal wage setting and hiring decisions. The paper contributes to a large body of literature that has considered the implications of reciprocity, loss aversion, and downward wage rigidity in labour markets ${ }^{1}$ by developing a tractable microeconomic model that allows a rigorous analysis of the asymmetries and irreversibility of wage and effort dynamics, and of their implications for the nature of the employment contract. We believe that gaining a deeper understanding of the incentives driving workers' and firms' behaviour when engaged in employment relationships is also particularly important in light of recent advances in the macroeconomic theory of labour market fluctuations (Elsby et al., 2015).

The basic premise of our theory is that there is contractual incompleteness over effort (Williamson, 1985); and that workers evaluate wage contracts relative to a reference 'fair'

\footnotetext{
${ }^{1}$ This literature spans from the first efficiency wage models developed by Akerlof (1982) and Akerlof and Yellen (1990), to the model of Bhaskar (1990) and to more recent applications of fairness and reciprocity in labour markets, such as, Danthine and Kurmann (2007), Eliaz and Spiegler (2014), and Benjamin (2015).
} 
wage. Central to our model is the inclusion of a 'morale function' in the worker's payoff, which consequently exhibits both positive and negative reciprocity stemming from their reference-dependent preferences: a wage above the reference wage increases morale and triggers supra-normal effort; a wage below the reference wage reduces morale and triggers sub-normal effort. This establishes a positive wage-effort relationship where, if the worker is loss averse, negative reciprocity is stronger than positive reciprocity. To the best of our knowledge our paper is the first that formally derives a link between reference dependence, loss aversion and the asymmetric nature of reciprocity from a worker's optimal behaviour. Although the relationship between loss aversion and negative reciprocity has already been conjectured in the empirical literature (see e.g. Fehr et al. (2009)), we think that rigorously formalising this idea will not only enable us to transparently analyse the implications of loss aversion for optimal wage setting, but will also allow us to derive new testable hypotheses. ${ }^{2}$ In addition we show that if a worker uses the past wage as their reference for fairness, any reciprocity response triggered by an initial wage change will eventually disappearreciprocity in our model is a temporary phenomenon. This implication is consistent with evidence on the dynamics of workers' reciprocity and supports the interpretation according to which reciprocity is temporary due to dynamic adaptation of the reference wage (see, for instance, Gneezy and List (2006), Mas (2006), and Sliwka and Werner (2017)).

In the second main contribution of the paper we explore the implications of the asymmetry and dynamics of reciprocity just discussed in a two-period employment relationship in which the evolution of the job-match productivity is uncertain. First, we show that in a situation in which the firm is facing a negative shock and has an incentive to decrease the worker's wage, consideration of the relatively large impact of negative reciprocity on output gives rise to downward wage rigidity for a range of negative shocks. ${ }^{3}$ Importantly,

\footnotetext{
${ }^{2}$ Our focus is on the interplay of loss aversion, reciprocity, optimal wage setting and hiring, but we are not the first to analyse the implications of loss aversion in labour markets (see, for instance, the static macroeconomic models of Bhaskar (1990), McDonald and Sibly (2001) and Ahrens et al. (2015)).

${ }^{3}$ To avoid confusion, we refer to wage rigidity as the acyclical behaviour of wages, i.e. when wages do not adjust to shocks (downward/upward or both); while the other most commonly used term in the literature, i.e. wage stickiness, refers to the less than proportional cyclicality of wages with respect to shocks. Hence, downward (nominal and real) wage rigidity is the tendency of wages to not fall during recessions. This has been widely documented in the empirical literature by looking at wage change distributions, which exhibit a high incidence of wage freezes with wage cuts less frequent than wage increases (see e.g. Nickell and Quintini (2003), Fehr and Goette (2005), Dickens et al. (2007)). Evidence that firms avoid cutting wages during recessions has also been reported by several field surveys (see, for instance, Campbell and Kamlani (1997), Bewley (1999), Agell and Bennmarker (2007), Babecký et al. (2010)).
} 
this is not a static result: due to the worker's adaptation to wage increases during periods of positive shocks, the firm will face a trade-off between wage cuts and negative reciprocity whenever, in any subsequent period, it is confronted with negative shocks. Downward wage rigidity may arise even at wage levels substantially higher than those with which the employment relationship had initially started. As we discuss in our analysis we identify an asymmetric adjustment cost around the past wage as a necessary ingredient for models of dynamic downward wage rigidity. While in the existing literature (such as Elsby (2009), Holden and Wulfsberg (2009), Eliaz and Spiegler (2014) and Kaur (2018)) this asymmetry is usually assumed by appealing to appropriate reduced form representations of behaviour, in our model we identify the worker's dynamic adaptation of the reference wage, and the relatively large cost to the firm of negative reciprocity (that stems from loss aversion) as the two behavioural mechanisms that lead to downward wage rigidity in a dynamic environment. As such, a key contribution of our paper to this literature is to provide a plausible and transparent micro-foundation for dynamic downward wage rigidity.

We believe our in-depth and more general approach to be particularly important for a theory of wage setting behaviour that aims to provide a rigorous analysis of the sources, and consequences, of downward wage rigidity in labour markets. In fact, thanks to this approach we are able to derive predictions on how the expectation of negative reciprocity and downward wage rigidity can affect a forward-looking firm's wage setting and hiring decisions, which is our third contribution. Our analysis is important in understanding whether the expectation of future downward wage rigidity also implies a more compressed wage growth throughout the employment relationship. While the literature on this subject has established that such an expectation leads to compression of wage increases (see Elsby (2009) and Benigno and Ricci (2011)), in contrast we show that this prediction might not hold in our model: a firm that expects to be more constrained by downward wage rigidity in the future is also facing a greater ex ante probability of subsequently laying off the worker. This reduces the expected duration of the employment relationship, and will therefore partially offset the incentive to compress wage increases to keep their worker's wage and reference wage low in the future. Moreover, we explore how these considerations affect the firm's hiring decisions through the influence on the firm's expected value of the 
employment relationship. We find that, independently of whether the initial hiring wage is compressed by the firm, the expectation of downward wage rigidity - and the anticipation of stronger negative reciprocity - unambiguously reduce the value of a new employment relationship, implying that the firm will hire less on average. This result contributes to the literature concerned with the effects of incumbent workers' downward wage rigidity on job creation (see the discussion in Elsby et al. (2016)) and suggests that expected rigidities in the wage of existing/incumbent workers can negatively affect firms' incentives to hire.

While there are several reduced-form models in the literature that feature downward wage rigidity (e.g. Elsby (2009), Holden and Wulfsberg (2009), Eliaz and Spiegler (2014), Benjamin (2015), and Kaur (2018)), to the best of our knowledge we are the first to analyse the dynamic implications of loss aversion, reciprocity and downward wage rigidity for a forward-looking firm's wage setting and hiring decisions, which is made possible only by taking an approach that explores the microeconomic foundations of behaviour.

The outline of the paper is as follows. We set out our model of asymmetric referencedependent reciprocity and optimal wage setting in Section 2. In Section 3 we explore the properties of the model for wage and effort dynamics, and we study their implications for the nature of the employment contract. Section 4 offers some concluding remarks. All proofs are contained in the appendix.

\section{Basic Set-Up}

We begin by considering an established worker-firm employment relationship for a single employment period to illustrate the mechanisms at work. We assume a setting of complete information. The worker is assumed to be reference dependent and loss averse: they evaluate wage contracts in relation to a reference 'fair' wage, which captures their perception of fairness and is taken as exogenous for the purpose of this section. A wage below the reference wage is perceived as unfair, while a wage above is perceived as a gift. At the start of the employment period the firm learns the match productivity and the worker's reference wage, and subsequently decides on the profit-maximising wage. After observing the wage and evaluating it in relation to their reference wage, the worker decides on the utility-maximising level of effort that generates output for the firm. Payoffs are then 
realised.

Wage setting is thus formalised as a sequential-move game in which the firm (the first mover) makes a take-it-or-leave-it wage offer to the worker (the second mover). Since the worker's belief of what should be a 'fair' wage is independent of the firm's actions, and the firm is assumed to be motivated only by profit, the game can be solved by backward induction. $^{4}$

\subsection{Payoffs}

We let $e$ denote effort of the worker, $w$ the wage paid, $r$ the reference wage, and $q$ the match productivity. The instantaneous profit function of the firm is given by

$$
\pi(w ; q, e)=y(q, e)-w
$$

where $y$ is the per-worker output (the price of which is normalised to one). We make the following assumption:

F1. $y_{e}, y_{q}>0, y_{e e}, y_{q q} \leq 0$ and $y_{q e}>0$.

We specify the worker's preferences by an additively separable utility function

$$
u(e ; w, r)=v(w)-d(e)+M(e ; w, r)
$$

where $v$ captures the worker's evaluation of the wage; $d$ represents the worker's intrinsic psychological net cost of productive activity ${ }^{5}$; and $M$ is the 'morale function' that depends

\footnotetext{
${ }^{4}$ In contrast to more general applications of 'psychological game theory' to intentions-based reciprocity (e.g., Rabin, 1993; Dufwenberg and Kirchsteiger, 2004), in our model reciprocity is only on the side of the worker; and the worker's perception of fairness is determined by a comparison of the wage to a wage they consider as fair - given by the reference wage - that is independent of the actions the firm could have taken had it not paid its chosen wage. As such, we do not need to consider beliefs, which would be necessary if we construct the fair wage from what could otherwise have been chosen. Nevertheless, the firm's choice of the wage conveys intention from the worker's perspective, and the firm's 'kindness' or 'unkindness' is judged by the worker in terms of whether the wage offer is above, equal, or below the reference wage. Whilst this is a straightforward conception of reciprocity, it is rich enough to allow us to capture many salient features of the employment relationship, and allows us to use simple backward induction to solve the game.

${ }^{5}$ For instance: $d(e)=c(e)-b(e)$, where $c$ and $b$ are respectively the physical/psychological cost and benefit of effort.
} 
on the worker's evaluation of the wage in relation to the reference wage:

$$
M(e ; w, r) \equiv e \cdot n(w \mid r)
$$

We assume that $n(w \mid r) \equiv \mu(v(w)-v(r))$ where $\mu$ is a gain-loss value function that exhibits loss aversion in the spirit of Kahneman and Tversky (1979) and Tversky and Kahneman (1991).

We impose the following assumptions:

W1. $v$ is twice continuously differentiable, $v^{\prime}>0, v^{\prime \prime}<0$ for all $w<\infty$ and $\lim _{w \rightarrow \infty} v^{\prime}(w)=$ 0.

W2. $d$ is twice continuously differentiable, $d^{\prime \prime}>0, d^{\prime}(0)<0$, and $\lim _{e \rightarrow \infty} d^{\prime}(e)=\infty$.

W3. $\mu$ is piecewise-linear so

$$
n(w \mid r)= \begin{cases}\eta[v(w)-v(r)] & \text { if } w \geq r \text { and } \\ \lambda \eta[v(w)-v(r)] & \text { if } w<r\end{cases}
$$

where $\eta>0$ and $\lambda \geq 1$.

These assumptions imply that $u(e ; w, r)$ is strictly concave in $e$ and always obtains a maximum for any wage and reference wage combination (it also implies that 'normal' effort-when the wage is equal to the reference wage - is positive, as we subsequently discuss). In assumption $\mathrm{W} 3, \eta$ captures the importance of gain-loss utility and $\lambda$ represents the worker's degree of loss aversion.

The morale function in (3) captures the psychological cost/benefit of productive effort associated with the worker's perception of fairness. If the wage exceeds the reference wage (it is perceived as a gift) the worker gains some additional benefit of productive effort and an increase in effort (a gift to the firm) will increase utility. If the wage falls short of the reference wage (it is perceived as unfair) there is a psychological cost of productive effort and a reduction in effort (an 'unkind' action towards the firm) increases utility. As such, the morale function implies the worker's payoff exhibits reciprocity, and since morale is linked to loss aversion, negative reciprocity is stronger than positive reciprocity. 


\subsection{The worker's choice of effort}

Given a reference wage $r$ and a wage offer $w$, the worker will seek to

$$
\max _{e \geq 0} v(w)-d(e)+e n(w \mid r)
$$

The necessary (and under our assumptions sufficient) first-order condition is

$$
-d^{\prime}(e)+n(w \mid r) \leq 0
$$

in which the inequality is replaced with an equality if $e>0$. To save on notational complexity, we henceforth assume an interior solution ${ }^{6}$ in which the optimal effort is given by

$$
\tilde{e}(w, r, \lambda)=d^{\prime-1}(n(w \mid r))= \begin{cases}d^{\prime}-1(\eta[v(w)-v(r)]) \equiv \tilde{e}(w, r)^{+} & \text {if } w>r \\ d^{\prime}-1(0) \equiv \tilde{e}^{n} & \text { if } w=r \\ d^{\prime-1}(\lambda \eta[v(w)-v(r)]) \equiv \tilde{e}(w, r, \lambda)^{-} & \text {if } w<r\end{cases}
$$

When $w=r$ the morale function is zero and the worker's utility is maximised by the value of effort such that $d^{\prime}(e)=0$, referred to as 'normal' effort and denoted $\tilde{e}^{n}$, which is positive (due to the inclusion of a net cost of productive activity with the properties imposed in Assumption W2) and independent of the wage. This is consistent with the idea that workers perceive positive satisfaction from engaging with productive activity. ${ }^{7}$ If the worker is paid a wage above their reference wage, they will positively reciprocate this gift with 'supra-normal' effort $\tilde{e}(w, r)^{+}>\tilde{e}^{n}$; while if the wage is set below their reference wage, they will negatively reciprocate this unfair wage by exerting 'sub-normal' effort $\tilde{e}(w, r, \lambda)^{-}<\tilde{e}^{n}$. The properties of the optimal effort function are summarised in the following theorem.

Theorem 1. For a given $r$, optimal effort $\tilde{e}(w, r, \lambda)$ is a continuous function of $w$ with

\footnotetext{
${ }^{6}$ In the proof of Theorem 1 we give a sufficient condition for the solution to be interior.

${ }^{7}$ Inspired by the findings reported in Bewley (2007) - that it is not wage levels but changes in wages that influence effort-normal effort should be a non-pecuniary concept and is therefore modelled as being independent of the wage. See, for example, the discussion in Altmann et al. (2014, Appendix). A similar assumption is also considered by Sliwka and Werner (2017), Kaur (2018) and Macera and te Velde (2018).
} 
$\tilde{e}_{w}(w, r, \lambda)>0$ and $\tilde{e}_{w w}(w, r, \lambda)<0$ for all $w \neq r, w<\infty$, and $\lim _{w \rightarrow \infty} \tilde{e}_{w}=0$. Moreover ${ }^{8}$

$$
\lim _{w \rightarrow r^{-}} \tilde{e}_{w}(w, r, \lambda)^{-}=\lambda \lim _{w \rightarrow r^{+}} \tilde{e}_{w}(w, r)^{+}
$$

so the effort function has a kink at $w=r$ if $\lambda>1$. For a given $w, \tilde{e}(w, r, \lambda)$ is a continuous function of $r$ with $\tilde{e}_{r}(w, r, \lambda)<0$ for all $w \neq r$. Finally, whilst $\tilde{e}(w, r, \lambda)$ above the reference wage is independent of $\lambda$, for all $w<r, \tilde{e}_{\lambda}(w, r, \lambda)<0$ and $\tilde{e}_{w \lambda}(w, r, \lambda)>0$.

This relationship between effort and the wage is illustrated in Figure 1.

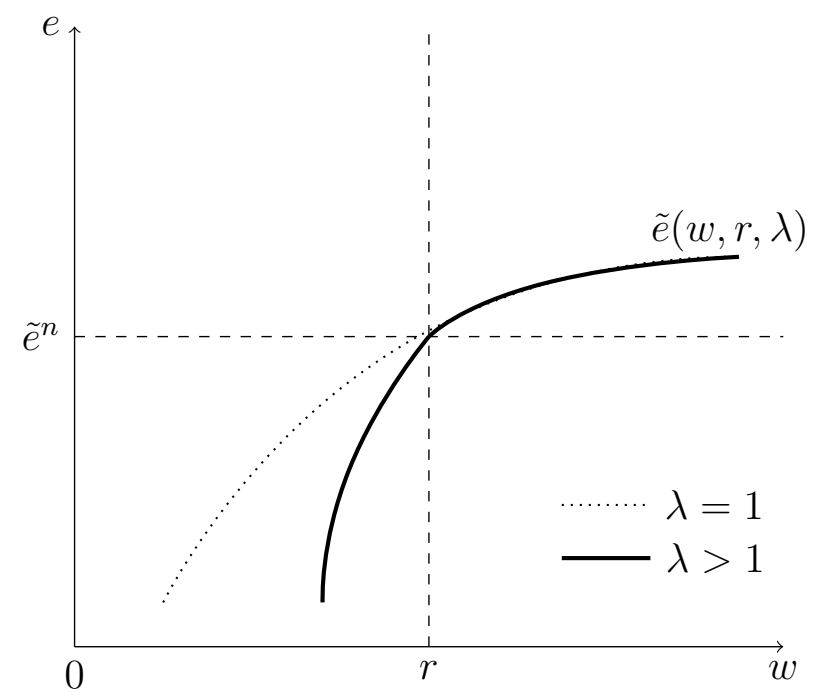

Figure 1:

Asymmetric reference-dependent reciprocity

The asymmetric nature of effort responses has the particular implication that for changes in the wage from an initial wage equal to the reference wage, the effect of negative reciprocity that results from a wage cut will be greater than the effect of positive reciprocity resulting from a wage increase. The extent of this 'asymmetric reference-dependent reciprocity' depends on the worker's degree of loss aversion. Indeed, if a worker is not loss averse $(\lambda=1)$, reciprocity is symmetric.

Our derived wage-effort relationship is consistent with the large body of evidence documenting the asymmetric nature of workers' reciprocity in response to wage changes (see, for instance, the anthropological evidence documented in Campbell and Kamlani (1997) and Bewley (1999); the field experiments of Kube et al. (2013) and Cohn et al. (2014); and the related literature surveyed in Bewley (2007), Fehr et al. (2009) and Malmendier

\footnotetext{
${ }^{8}$ We use the notation $\lim _{w \rightarrow r^{-(+)}}$to denote the limit as $w \rightarrow r$ from below (above).
} 
et al. (2014)). Moreover, our model formally identifies loss aversion as the psychological foundation for why negative reciprocity is stronger, therefore providing a micro-foundation for reduced-form effort/production functions exhibiting asymmetric reciprocity that are commonly assumed in the literature (e.g. Elsby (2009), Eliaz and Spiegler (2014) and Kaur (2018)) but that are not explicitly modelled.

\subsection{The firm's wage setting rule}

Next we consider the firm's problem in setting the wage given that it anticipates the behaviour of the worker. After observing the worker's reference wage $r$ and match productivity $q$, the firm will seek to maximise its profit given that the worker's effort is determined as in (6). As such, the firm's problem is to

$$
\max _{w \geq 0} y(q, \tilde{e}(w, r, \lambda))-w
$$

Since our focus is on wages (and effort) in established employment relationships, other than requiring wages to be non-negative we choose not to explicitly model the worker's participation constraint and suppose that any wage offer made by the firm is accepted. ${ }^{9}$

The properties of the worker's optimal effort function $\tilde{e}(w, r, \lambda)$ derived in Theorem 1 , notably that there is a kink at $w=r$ for a loss averse worker, combined with Assumption F1, allow us to derive the optimal wage setting rule accounting for the implied kink in the profit function at $w=r$.For $w \neq r$ the optimal wage is characterised by the following first-order condition

$$
y_{e}(q, \tilde{e}(w, r, \lambda)) \tilde{e}_{w}(w, r, \lambda)-1 \leq 0
$$

where the inequality is replaced with an equality if $w>0$ which we henceforth assume. ${ }^{10}$ The first term in (7) captures the marginal product of labour induced by a wage change, and

\footnotetext{
${ }^{9}$ This is for clarity of exposition. In the Appendix we explicitly derive the worker's participation constraint (in a dynamic context) and show that it is straightforward to impose a condition on the exogenous variables of the model such that it is never binding. We could also replace the constraint $w \geq 0$ with a positive constant representing an outside option but while this adds an additional threshold to the model (making it more complicated) it doesn't add anything to our analysis as we consider a partial equilibrium framework. That said, reservation wages might be relevant in a richer macroeconomic framework in which the worker's initial reference wage is endogenous and, in particular, dependent on the state of the labour market.

${ }^{10}$ This requires the marginal product of labour to be sufficiently high when effort is at its lowest, so that $y_{e}(q, \tilde{e}(0, r, \lambda)) \tilde{e}_{w}(0, r, \lambda)-1>0$.
} 
the per-worker marginal cost is 1 . The resulting optimal wage setting rule is characterised by two productivity thresholds: a lower threshold $q^{l}$, which is such that if $q<q^{l}$ then profit is maximised where the marginal product of labour equals the marginal cost at a wage strictly below the reference wage; and an upper threshold $q^{u}$, which is such that if $q>q^{u}$ then profit is maximised by equating the marginal product of labour with the marginal cost at a wage exceeding the reference wage. Instead, if $q^{l} \leq q \leq q^{u}$ profit will be maximised at the kink, i.e. where $w=r$. The productivity thresholds $q^{l}(r, \lambda)$ and $q^{u}(r)$ are respectively characterised by the value of $q$ such that

$$
\begin{gathered}
\lim _{w \rightarrow r^{-}} y_{e}\left(q, \tilde{e}(w, r, \lambda)^{-}\right) \tilde{e}_{w}(w, r, \lambda)^{-}-1=0 ; \text { and } \\
\lim _{w \rightarrow r^{+}} y_{e}\left(q, \tilde{e}(w, r)^{+}\right) \tilde{e}_{w}(w, r)^{+}-1=0 .
\end{gathered}
$$

If the match productivity falls below a reservation threshold $\underline{q}(r, \lambda)$, implicitly defined by the zero-profit condition

$$
\pi(\tilde{w}(r, q, \lambda) ; q, \tilde{e}(\tilde{w}(r, q, \lambda), r, \lambda))=0
$$

the employment relationship will be terminated.

These properties are summarised in the following theorem.

Theorem 2. The optimal wage $\tilde{w}(r, q, \lambda)$ is a continuous function of $q$ and $r$ and is given by

$$
\tilde{w}(r, q, \lambda)= \begin{cases}\tilde{w}(r, q)^{+} & \text {if } q>q^{u}(r) \\ r & \text { if } q^{l}(r, \lambda) \leq q \leq q^{u}(r) \\ \tilde{w}(r, q, \lambda)^{-} & \text {if } q<q^{l}(r, \lambda),\end{cases}
$$

where $\tilde{w}(r, q)^{+}>r$ and $\tilde{w}(r, q, \lambda)^{-}<r$ are implicitly defined by (7). Moreover:

a) $\tilde{w}_{q}(r, q, \lambda)>0$ for all $q \in[\underline{q}(r, \lambda), \infty) \backslash\left[q^{l}(r, \lambda), q^{u}(r)\right]$;

b) $\tilde{w}_{r}(r, q, \lambda)>0$ for all $[\underline{q}(r, \lambda), \infty)$; and

c) $\tilde{w}_{\lambda}(r, q, \lambda)>0$ for all $\left[\underline{q}(r, \lambda), q^{l}(r, \lambda)\right)$.

In addition, the productivity thresholds have the following properties: 
d) $q^{l}(r, \lambda)<q^{u}(r)$ for all $\lambda>1$ and $q^{l}(r, \lambda)=q^{u}(r)$ if $\lambda=1$;

e) $q^{u \prime}(r)>0, q_{r}^{l}(r, \lambda)>0$; and

f) $q_{\lambda}^{l}(r, \lambda)<0$.

The reservation productivity has the properties that $\underline{q}_{r}(r, \lambda)>0$ and $\underline{q}_{\lambda}(r, \lambda) \geq 0$, where the final inequality is strict if $\underline{q}(r, \lambda)<q^{l}(r, \lambda)$.

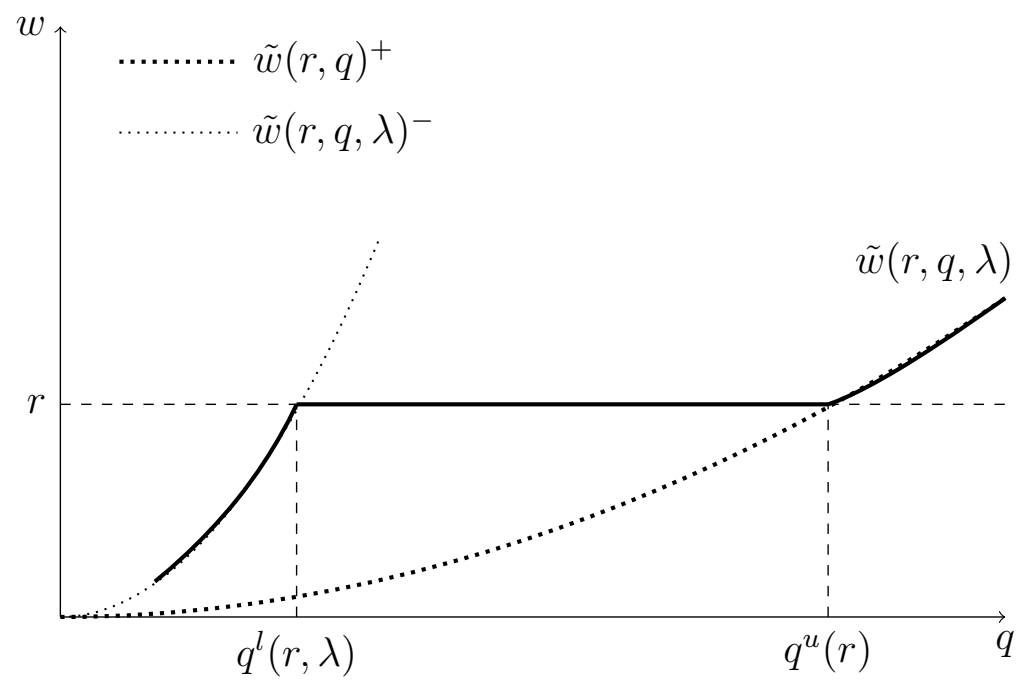

Figure 2:

The wage setting rule

The main features of the firm's optimal wage when facing a loss averse worker are illustrated in Figure 2. The optimal wage is non-decreasing in the match productivity and there is a range of match productivity within which the wage is not adjusted. We refer to this as the 'range of rigidity', which is non-empty if the worker is loss averse as in this region the benefit of reducing the wage will be offset by the cost generated by the worker's negative reciprocity response. Note that a firm employing a worker with a greater degree of loss aversion will be less willing to suffer the relatively high cost of negative reciprocity for a given match productivity (i.e. the range of rigidity becomes larger as $q_{\lambda}^{l}(r, \lambda)<0$ ), and if $q$ is low enough that the firm wishes to pay $\tilde{w}(r, q, \lambda)^{-}(<r)$, it will have an incentive to attenuate some of the effect from the stronger negative reciprocity, by paying a higher wage: $\tilde{w}_{\lambda}(r, q, \lambda)^{-}>0$. Negative reciprocity not only tempers the firm's incentive to cut the wage, it also reduces the extent to which the wage is cut. ${ }^{11}$ Finally, the more loss

\footnotetext{
${ }^{11}$ This implication has been theoretically derived, and empirically corroborated, in a model of firm-level
} 
averse a worker is, the higher is the reservation productivity that the firm requires from the employment relationship for it to be profitable: $\underline{q}_{\lambda}(r, \lambda)>0$, since a higher $\lambda$ reduces per-worker output and increases the per-worker labour cost.

Our derivation of reciprocity in the context of employment contracts is related to the work of Danthine and Kurmann (2006, 2007, 2010), Sliwka and Werner (2017) and Macera and te Velde (2018). Danthine and Kurmann explore the macroeconomic implications of reciprocity à la Rabin (1993) for wage and unemployment dynamics. However, their model does not capture negative reciprocity, and generates wage rigidity only under certain assumptions about the nature of shocks, workers' reference wages and the functional form of the workers' gift. Sliwka and Werner (2017) build on the conceptual framework of Cox et al. (2007) and develop a model of effort in which — depending on their 'emotional state'the worker also cares about the firm's payoff. However, they do not analyse the related implications for optimal wage setting. ${ }^{12}$ In a more recent paper Macera and te Velde (2018) develop a model of reference-dependent reciprocity and find that fully surprising wage gifts lead to higher effort than fully anticipated wage gifts. However, in their model reciprocity is asymmetric only for small deviations of the wage from the reference wage.

Our application of reciprocity is fundamentally different from Sliwka and Werner (2017) and Macera and te Velde (2018) which, essentially, are all based on the worker's consideration of the firm's payoff. We believe our model to be more plausible in capturing real world employment relationships since - as also argued by Dufwenberg and Kirchsteiger (2000, p.1071) —informational problems characterising actual labour relations can make it hard for workers to compare their payoff with that of their employer. Moreover, none of these papers analyse the implications of loss aversion and asymmetric reciprocity for downward wage rigidity, wage compression and hiring in a dynamic environment, which is one of the key contributions of our paper.

wage bargaining by Holden and Wulfsberg (2014), who show that "even if the wage is cut, the resulting wage will be higher than if the wage-setting process had been completely flexible". In contrast with their theoretical model, our theory attributes this result to the worker's extent of negative reciprocity.

${ }^{12}$ Despite being based on different assumptions regarding the worker's preferences and reciprocity motives, our model and the one of Sliwka and Werner (2017) yield a similar theoretical prediction concerning the worker's optimal effort response to wage changes. In this respect we would like to acknowledge that the first version of our paper appeared in July 2015 (as a SIRE Discussion Paper SIRE-DP-2015-57). Therefore, we believe our framework and the one of Sliwka and Werner (2017) were likely to have been developed independently. 


\section{Adaptation, Loss Aversion and the Employment Contract}

We now turn to explore the dynamic implications of asymmetric reciprocity and reference dependence for optimal wage setting and hiring in a two-period dynamic environment. In so doing we introduce uncertainty around the evolution of the match productivity and, inspired by the literature that suggests reference points are influenced by previous contractual arrangements, we model the reference wage as being endogenously determined by the past wage. ${ }^{13}$ To capture these features, we impose the following two assumptions:

D1. The match productivity $q_{t}$ follows a Markov process described by the cumulative distribution function $F\left(q_{1} \mid q_{0}\right)$, $q_{0}$ given.

D2. The worker's reference wage evolves according to the adaptation rule: $r_{1}=w_{0}, r_{0}$ given.

The timing of the model is as follows. At the beginning of the first employment period, the match productivity $q_{0}$ and the exogenously-given reference wage $r_{0}$ are observed. ${ }^{14}$ The firm then decides whether to offer a wage contract to the worker to start the employment relationship. ${ }^{15}$ If so, then at the beginning of the second employment period the match

\footnotetext{
${ }^{13}$ The assumption that past wage contracts serve as a reference point is consistent with a large body of evidence documented in the labour market literature on reference wage formation as well as by other behavioural science sub-disciplines concerned with reference point formation. See, for instance, the seminal experiment of Kahneman et al. (1986); the field experiments of Gneezy and List (2006), Mas (2006), Chemin and Kurmann (2014); and the laboratory experiments of Clark et al. (2010), Gächter and Thöni (2010), Koch (2017) and Sliwka and Werner (2017) among others. Adaptation to past wage contracts is also supported by several anthropological studies (see the survey of Bewley (2007)) and has been coupled with the psychological notion of adaptation, or habituation, popular in social psychology (see Kahneman and Thaler (1991) and Baucells and Sarin (2010) for a review of this early literature). Moreover, the idea that ex-ante contracts serve as entitlements for future renegotiations was advanced by Hart and Moore (2008) and further explored in Herweg and Schmidt (2012) in the literature on incomplete contracts. The laboratory experiments of Fehr et al. (2011, 2014), Bartling and Schmidt (2015) and Herz and Taubinsky (2018) provide strong support for this hypothesis.

${ }^{14}$ One could consider many influences on the reference wage of a newly hired worker, such as the wage they received in a previous employment relationship, the state of the labour market, or their next best offer. So long as the firm knows the initial reference wage our analysis can be used as described. If the firm doesn't know the initial reference wage, but knows the distribution from which it is drawn, then it would consider the expected value of the reference wage when setting the wage for the first employment period. Hence, the features of the wage setting rule would be the same as we describe in our analysis, since we assume reference wage adaptation (Assumption D2). Given these considerations, we proceed assuming that the initial reference wage is known and, as we have a partial equilibrium model, can remain agnostic about its determination.

${ }^{15}$ As in Section 2, we assume that any non-negative wage offer is accepted by the worker, so this is solely determined by whether the match is profitable for the firm.
} 
productivity changes stochastically to a new value $q_{1}$, and the worker adapts their reference wage to the wage paid in the initial period of employment. After observing $q_{1}$, and inferring the worker's new reference wage, the firm considers whether it wants to continue the employment relationship and, if so, whether to adjust the wage in light of the change in match productivity.

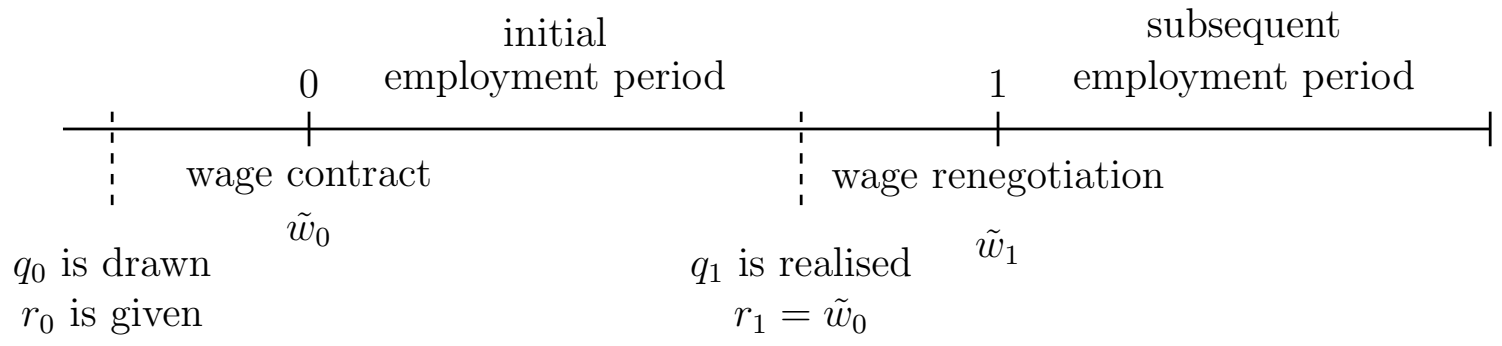

Figure 3:

Two-period employment relationship time-line.

The forward-looking firm therefore faces a two-period dynamic optimisation problem under uncertainty. Letting $\delta$ represent the firm's discount factor, this is characterised by

$$
\begin{aligned}
\max _{\left\{w\left(r_{t}, q_{t}, \lambda\right)\right\}_{t=0}^{1}} & \mathbb{E}_{0}\left[\sum_{t=0}^{1} \delta^{t} \pi\left(w_{t} ; q_{t}, e_{t}\right)\right] \\
\text { s.t. } & e_{t}=\tilde{e}\left(w_{t}, r_{t}, \lambda\right), \\
& r_{1}=w_{0}, \\
& r_{0}, q_{0} \quad \text { given. }
\end{aligned}
$$

So that we can transparently capture the effect of adaptation of reference wages, our model abstracts from any dynamic implications of the worker's choice of effort, such as effort directly influencing the subsequent wage offer. Absent this link the worker can be seen as choosing effort to maximise their per-period utility, in accordance with the optimal effort function (6) derived in Section 2.

The analysis that follows is divided in two parts: first we illustrate the wage and effort dynamics by considering a myopic firm $(\delta=0)$, and highlight that downward wage rigidity may occur as a result of the worker's reference wage adaptation combined with loss aversion. Then we consider a forward-looking firm $(\delta>0)$ and characterise the optimal employment contract that solves the problem in (9) to explore its properties in light of the novel behavioural elements introduced in our model. 


\subsection{Wage and effort dynamics: an illustration}

In this section we illustrate some dynamic properties of the model by considering a simple parameterised example with a myopic firm $(\delta=0)$. We focus the analysis around two interdependent features of wage and effort dynamics: i) downward wage rigidity; and ii) the temporary nature of worker's reciprocity.

Consistent with Assumptions F1 and W1-W3 of Section 2, consider the following functional forms: per-worker output $y(q, e)=q e$; worker's utility from the wage $v(w)=\log w$; and their net cost of productive activity $d(e)=e^{2} / 2-b e$, with $b>0$. Denoting $\tilde{e}\left(w_{t}, r_{t}, \lambda\right)=$ $\tilde{e}_{t}$ and $\tilde{w}\left(r_{t}, q_{t}, \lambda\right)=\tilde{w}_{t}$, in each period $t=\{0,1\}$ the worker's optimal effort function and the firm's optimal wage take the following simple forms:

$$
\tilde{e}_{t}=\left\{\begin{array}{ll}
\tilde{e}^{n}+\eta\left[\log w_{t}-\log r_{t}\right] & \text { if } w_{t}>r_{t} \\
\tilde{e}^{n} & \text { if } w_{t}=r_{t} \\
\tilde{e}^{n}-\lambda \eta\left[\log r_{t}-\log w_{t}\right] & \text { if } w_{t}<r_{t}
\end{array} \quad \tilde{w}_{t}= \begin{cases}\eta q_{t} & \text { if } q_{t}>q^{u}\left(r_{t}\right) \\
r_{t} & \text { if } q^{l}\left(r_{t}, \lambda\right) \leq q_{t} \leq q^{u}\left(r_{t}\right) \\
\lambda \eta q_{t} & \text { if } q_{t}<q^{l}\left(r_{t}, \lambda\right)\end{cases}\right.
$$

where $\tilde{e}^{n}=b$;

$$
q^{l}\left(r_{t}, \lambda\right)=\frac{r_{t}}{\lambda \eta} \quad \text { and } \quad q^{u}\left(r_{t}\right)=\frac{r_{t}}{\eta}
$$

and we assume that in both the initial and subsequent employment periods the match is profitable.

Consider a worker characterised by a relatively high match productivity $q_{0}>q^{u}\left(r_{0}\right)$ such that the firm will find it profitable to hire them and pay a wage gift $\tilde{w}_{0}=\eta q_{0}\left(>r_{0}\right)$, which is positively reciprocated by supra-normal effort $\tilde{e}_{0}>\tilde{e}^{n}$ in the first employment period. This is illustrated in Figure 4a below. As the employment relationship passes into the second employment period, the worker adjusts their feelings of entitlement, adapting their reference wage to their initial wage: $r_{1}=\tilde{w}_{0}=\eta q_{0}$. This 'shifts' the wage-setting rule, as illustrated in Figure 4b: the reference wage increases, the lower threshold increases to $q^{l}\left(r_{1}\right)=r_{1} /[\lambda \eta]=q_{0} / \lambda$, and the upper threshold increases to $q^{u}\left(r_{1}\right)=r_{1} / \eta=q_{0}$.

If, in the subsequent employment period, the match productivity remains unchanged so that $q_{1}=q^{u}\left(r_{1}\right)$, optimal wage setting implies $\tilde{w}_{1}=r_{1}\left(=\tilde{w}_{0}\right)$. However notice that whilst the initial wage $\tilde{w}_{0}$ was positively reciprocated by the worker in period 0 , after reference wage adaptation the worker has an updated sense of entitlement and now perceives this 
(a) Initial Contract $t=0$

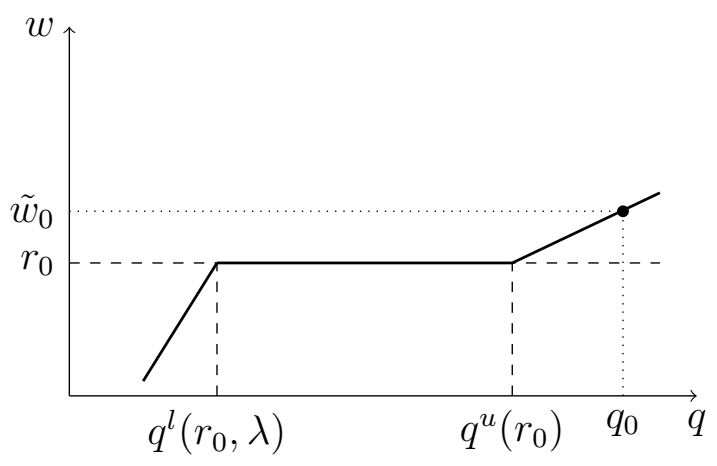

(b) Renegotiation $t=1$

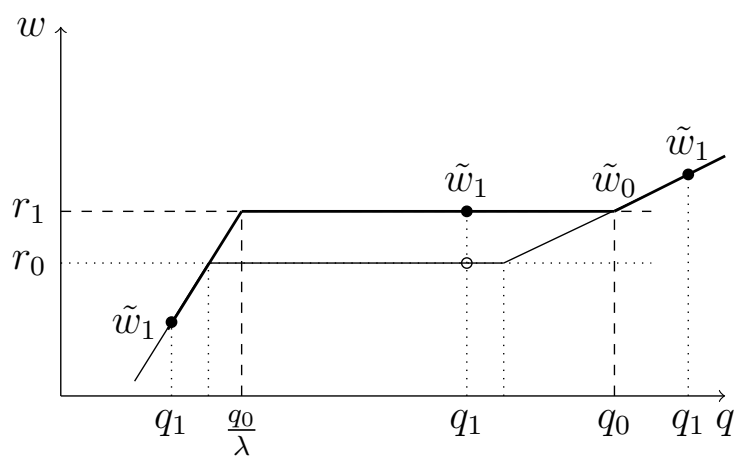

Figure 4:

Reference wage adaptation and downward wage rigidity.

wage as fair, meaning that effort is merely normal $\tilde{e}_{1}=\tilde{e}^{n}$. Hence, due to reference wage adaptation reciprocity is a temporary phenomenon. This implication of the model is consistent with the evidence reported by field surveys that the positive effects of a wage gift on morale and effort are believed to be only temporary by firms' managers (e.g. Campbell and Kamlani (1997), Bewley (1999)). It also supports the interpretation according to which - in field experiments - positive reciprocity quickly disappears as workers get used to the wage they receive (see, for instance, Gneezy and List (2006), Mas (2006) and Cohn et al. (2014)). Evidence of such effort dynamics has also recently been documented in the laboratory experiment of Sliwka and Werner (2017), which also corroborates the hypothesis of reference wage adaptation. ${ }^{16}$ We define this adjustment of effort over time as dynamic 're-normalisation' of effort.

If the match productivity increases $q_{1}>q_{0}$, the firm will instead find it optimal to increase the wage $\tilde{w}_{1}=\eta q_{1}>r_{1}\left(=\tilde{w}_{0}\right)$, to benefit from the gift being reciprocated by supra-normal effort. On the other hand, if the match productivity decreases $q_{1}<q_{0}$, whether the wage is adjusted downward depends on how large the negative shock is. As illustrated in Figure $4 \mathrm{~b}$, only if $q_{1}<q_{0} / \lambda$ will the firm implement a wage cut $\tilde{w}_{1}=\lambda \eta q_{1}<r_{1}$ $\left(=\tilde{w}_{0}\right)$. As such, a fall in match productivity over time is not necessarily followed by a

\footnotetext{
${ }^{16}$ Sliwka and Werner (2017) conduct a laboratory experiment in which individuals work on a real-effort task and are paid different wage profiles which vary in the frequency and size of wage increases. They find that the positive effect on effort of a wage increase only lasts one period and that in the following periods, absent subsequent increases in the wage, working performance converges back towards the level associated with a constant wage. Interestingly, the field experiment by Kube et al. (2013) also indicates that negative reciprocity is more persistent than positive reciprocity. In light of our theory this evidence suggests that reference wage adaptation, which drives the temporary nature of reciprocity, may also be asymmetric: workers adapt more rapidly to wage increases than to wage cuts (see Fongoni (2018a) for a preliminary theoretical exploration of this hypothesis).
} 
wage cut: the worker's reference wage adaptation implies that, if the match productivity only moderately decreases $q_{0} / \lambda \leq q_{1}<q_{0}$, the firm will optimally freeze the wage. The negative effect of what would now be perceived as an unfair wage cut, borne through negative reciprocity, will be larger than the benefit of paying a lower wage, hence the firm will avoid inciting such negative reciprocity by keeping the wage equal to the worker's reference wage $\tilde{w}_{1}=r_{1}\left(=\tilde{w}_{0}\right)$. To draw a more direct link with the empirical literature on downward wage rigidity (e.g. Dickens et al. (2007)), Figure 5 illustrates the distribution of log-wage changes, implied by our model, to a log-normally distributed shock around $q_{0}$ in period 1 , comparing the case of symmetric $(\lambda=1)$ vs. asymmetric reference-dependent reciprocity $(\lambda>1)$.

(a) $\lambda=1$

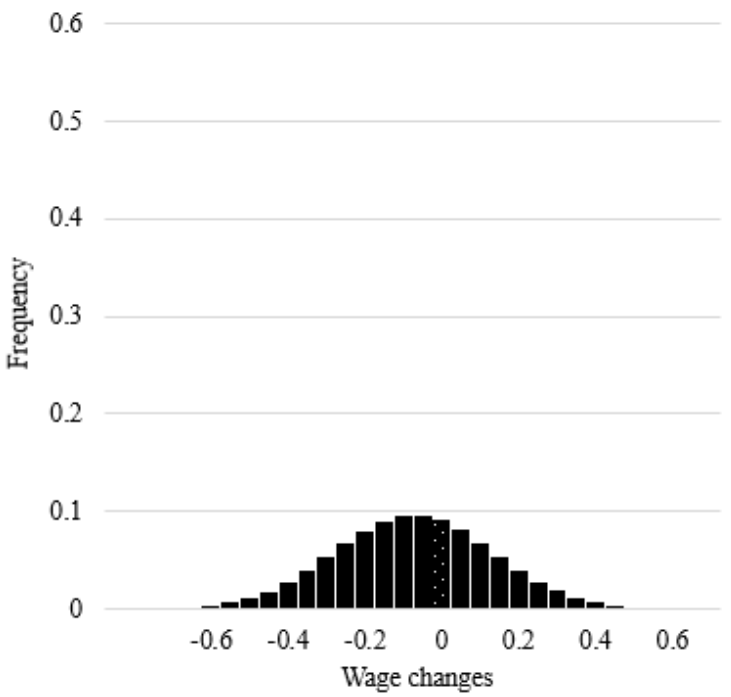

(b) $\lambda>1$

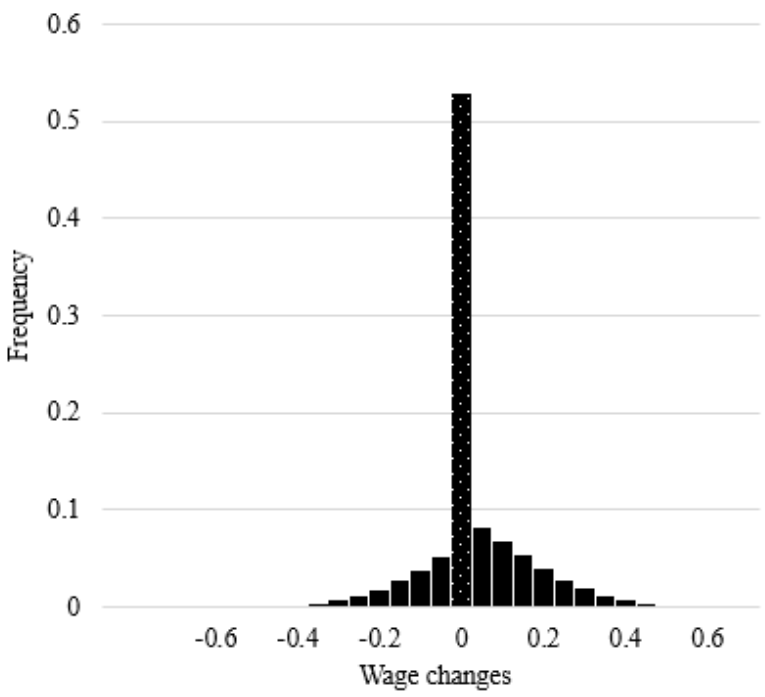

Figure 5:

Theoretical distributions of log-wage changes

Note: Simulated distributions of log-wage changes from the model based on the following assumptions and parameter values: the initial productivity and reference wage are $q_{0}=10$ and $r_{0}=1 ; \eta=1$ and the loss aversion parameter is $\lambda=1$ in Figure $5 \mathrm{a}$ and $\lambda=1.8$ in Figure $5 \mathrm{~b}$ (the experimental literature on loss aversion estimates $\lambda \in[1.43,4.8]$; see Abdellaoui et al. (2007) for a review); $q_{1}=q_{0}+\varepsilon$, where the shock $\varepsilon$ is $\log$-normally distributed around 0 with variance 10 , so that $\log q_{1} \sim \mathcal{N}\left(q_{0}, 10\right)$; and normal effort is set as $\tilde{e}^{n} \equiv b=10$ to ensure the employment relationship remains profitable even for large negative shocks. The number of simulations is 10,000 .

Notice that the downward wage rigidity implied by our model is not a static result. By virtue of the worker's (one-period) adaptation to wage increases during periods of positive productivity shocks, the firm will face the marginal trade-off between a wage cut and negative reciprocity at any subsequent employment period characterised by a fall in productivity. Downward wage rigidity may arise even at wage levels substantially 
higher than those with which the employment relationship had initially started. As such our theory formally demonstrates that downward wage rigidity is an inherent property of employment contracts in a dynamic environment, and identifies an asymmetric adjustment cost around the past wage as a key necessary ingredient: the marginal cost of cutting the wage needs to be larger than the marginal benefit of increasing it; and for this asymmetry to be always present in a dynamic environment it is also necessary for it to be always centered around the past wage.

Models of wage setting that generate dynamic downward wage rigidity thanks to these features are those of Elsby (2009), Holden and Wulfsberg (2009), Eliaz and Spiegler (2014), and Kaur (2018). However, these models are based on a reduced-form approach: both Elsby (2009) and Kaur (2018) consider a reduced-form effort function with a kink at the past wage; Holden and Wulfsberg (2009) consider a utility function that exhibits a kink at the point where the wage is equal to the past wage; and Eliaz and Spiegler (2014) consider a reduced-form production function in which output falls disproportionately if wages are set below the worker's lagged expectations about the wage. ${ }^{17}$ While reducedform approaches are useful from a modelling perspective, they remain mute on the actual sources of downward wage rigidity. In contrast, our model identifies the worker's dynamic adaptation of the reference wage, and the relatively large cost to the firm of negative reciprocity that derives from loss aversion, as the two key behavioural mechanisms that lead to dynamic downward wage rigidity. As such, one contribution of our paper to this literature is to provide a deeper understanding of the actual behavioural forces behind the asymmetries and irreversibility that characterise employment contracts.

Perhaps closest in spirit to our approach is the contribution of Benjamin (2015) who considers an inequity aversion framework (Fehr and Schmidt, 1999), as opposed to reciprocity, to derive downward wage rigidity and study the implications for a firm's wage set-

\footnotetext{
${ }^{17}$ As they show in an appendix, Eliaz and Spiegler (2014) can derive their reduced-form production function from a simple model that yields an expression for discretionary effort: if a worker is paid a wage at least equal to their reference wage, the worker is assumed to exert effort normalised to unity (see p. 195); if they are paid an unfair wage below their reference wage, effort is zero. Hence, they capture an extreme form of negative reciprocity: a wage cut below the reference wage, no matter how small, will induce a worker to exert zero discretionary effort, leaving the adverse effect on output to be randomly determined by a parameter that represents the incompleteness of the labour contract. In contrast, our model identifies the severity of the adverse effect of a wage cut on output by a combination of a worker's degree of loss aversion (which determines the strength of negative reciprocity) and the size of the wage cut.
} 
ting behaviour. The paper establishes that inequity-aversion concerns between the worker and the firm, combined with loss aversion on the side of the worker, lead to downward wage rigidity. Despite this implying that loss aversion is a necessary feature to explain downward wage rigidity in a model of inequity aversion, which is similar to our conclusion in a model of reciprocity, we believe our approach to be more satisfactory than that of Benjamin (2015). First, to generate downward wage rigidity Benjamin (2015) requires several additional restrictions on the model which include: the use of specific functional forms and numerical values for parameters; the assumption that the worker's utility is kinked where their surplus equals the firm's surplus; and, in addition, that the worker is loss averse around a 'reference transaction' in the domain of wages and effort. ${ }^{18}$ Second, some of the predictions of Benjamin (2015) in terms of the dynamics of effort are hard to reconcile with the evidence on this discussed above. ${ }^{19}$ In contrast, our model is consistent with evidence and is also simpler as we only assume reference dependence and loss aversion in the domain of wages. Finally, our model generates a distribution of wage changes (as illustrated in Figure 5), that is closer to reality than that predicted by the model of Benjamin (2015) which exhibits a gap in the distribution below zero.

We believe our approach to be important for a theory of wage setting behaviour that aims to provide a plausible account of the sources, and consequences, of downward wage rigidity. The advantages of this in-depth and more general approach are the following. First, identifying the sources behind these asymmetries and irreversibility is not only important from a purely positive scientific stance, but it is also useful from a normative perspective. For instance, our conceptual framework could be used by compensation managers when deciding on wage profiles, or by governments when designing policies that could affect workers' reference wages and - in light of our model - also effort and wages. Second, and as we turn to next, our modelling approach allows us to rigorously analyse the complex relationship between loss aversion, asymmetric reciprocity, downward wage rigidity

\footnotetext{
${ }^{18}$ The validity of some of these could be brought into question. While there is plenty of evidence that individuals are loss averse over monetary/material outcomes such as wages, we find it harder to think of what loss aversion in the domain of effort - and the kink around the point in which the worker/firm's surpluses are equal - actually means (as well as what determines the 'reference effort level' in the reference transaction).

${ }^{19}$ The model of Benjamin generates the prediction that effort will be higher-relative to the previous period - when the firm freezes the wage, and also when the shock is so negative that the firm optimally cuts the wage.
} 
and wage compression in a dynamic environment, and to subsequently study the related implications for a forward-looking firm's hiring decision. While dynamic downward wage rigidity also follows from the models discussed above, the theoretical predictions that we derive in what follows are unique to our approach.

\subsection{The optimal employment contract}

We now turn back to the general model and analyse the properties of a forward-looking firm's wage setting and hiring decision in light of the behavioural mechanisms just discussed which, whilst considered in the context of a parameterised model for illustration, apply equally to the general model.

We denote by $J_{t}\left(r_{t}, q_{t}\right)$ the firm's value function of the employment relationship in period $t=\{0,1\}$. The functional equation corresponding to the firm's sequence problem in (9) can therefore be written as:

$$
\begin{aligned}
J_{0}\left(r_{0}, q_{0}\right)= & \max _{w_{0}}\left\{\pi\left(w_{0} ; q_{0}, \tilde{e}\left(w_{0}, r_{0}, \lambda\right)\right)+\delta \mathbb{E}_{0}\left[J_{1}\left(w_{0}, q_{1}\right) \mid q_{0}\right]\right\} \\
& \text { where } J_{1}\left(r_{1}, q_{1}\right)=\max _{w_{1}} \pi\left(w_{1} ; q_{1}, \tilde{e}\left(w_{1}, r_{1}, \lambda\right)\right) .
\end{aligned}
$$

Due to reference wage adaptation $\left(r_{1}=w_{0}\right)$ the expected continuation value of the employment relationship $\mathbb{E}_{0}\left[J_{1}\left(w_{0}, q_{1}\right) \mid q_{0}\right]$ now also depends on the initial wage. Recognising that the lay-off reservation productivity in period 1 may fall anywhere in the support of the distribution of match productivity, to ease notational burden we make the assumption that the parameters of the model are such that $\underline{q}\left(w_{0}, \lambda\right)<q^{l}\left(w_{0}, \lambda\right)$. Hence, the expected continuation value of the employment relationship can be expressed as

$$
\begin{aligned}
\mathbb{E}_{0}\left[J_{1}\left(w_{0}, q_{1}\right) \mid q_{0}\right]= & \int_{\underline{q}\left(w_{0}, \lambda\right)}^{q^{l}\left(w_{0}, \lambda\right)} J_{1}\left(w_{0}, q_{1}\right)^{-} \mathrm{d} F\left(q_{1} \mid q_{0}\right)+ \\
& \int_{q^{l}\left(w_{0}, \lambda\right)}^{q^{u}\left(w_{0}\right)} J_{1}\left(w_{0}, q_{1}\right)^{=} \mathrm{d} F\left(q_{1} \mid q_{0}\right)+\int_{q^{u}\left(w_{0}\right)}^{\infty} J_{1}\left(w_{0}, q_{1}\right)^{+} \mathrm{d} F\left(q_{1} \mid q_{0}\right),
\end{aligned}
$$

where $J_{1}\left(w_{0}, q_{1}\right)^{-;=;+}$represents the continuation value of the employment relationship when $w_{1}<w_{0} ; w_{1}=w_{0} ; w_{1}>w_{0}$, in which effort is given by $\tilde{e}\left(w_{1}, w_{0}, \lambda\right)^{-} ; \tilde{e}^{n} ; \tilde{e}\left(w_{1}, w_{0}\right)^{+}$. This expression highlights that the firm faces different realisations of future profit when 
setting the initial wage $w_{0}$, depending on whether the subsequent match productivity $q_{1}$ is below, within or above the range of rigidity $\left[q^{l}\left(w_{0}, \lambda\right), q^{u}\left(w_{0}\right)\right]$. Attentive observation of equation (11) allows us to infer two important insights: when setting the wage in the initial employment period the firm influences both the expected continuation value of the employment relationship in each of the three scenarios and the range of match productivity over which these scenarios occur.

Define the marginal effect of a wage increase in period 0 on the expected future profit in period 1 as

$$
\Phi\left(w_{0}, \lambda\right) \equiv \frac{\partial}{\partial r_{1}} \int_{\underline{q}\left(w_{0}, \lambda\right)}^{\infty} J_{1}\left(w_{0}, q_{1}\right) \mathrm{d} F\left(q_{1} \mid q_{0}\right) .
$$

We demonstrate in the following lemma that higher initial wages are always detrimental to expected future profit.

Lemma 1. For all $\lambda \geq 1$, a higher initial wage reduces the expected continuation value of the employment relationship:

$$
\Phi\left(w_{0}, \lambda\right)=\int_{\underline{q}\left(w_{0}, \lambda\right)}^{q^{l}\left(w_{0}, \lambda\right)} y_{e} \tilde{e}_{r}\left(\tilde{w}_{1}, w_{0}, \lambda\right)^{-} \mathrm{d} F-\int_{q^{l}\left(w_{0}, \lambda\right)}^{q^{u}\left(w_{0}\right)} 1 \mathrm{~d} F+\int_{q^{u}\left(w_{0}\right)}^{\infty} y_{e} \tilde{e}_{r}\left(\tilde{w}_{1}, w_{0}\right)^{+} \mathrm{d} F<0 .
$$

When setting the initial wage in a dynamic environment a forward-looking firm will therefore account for an additional expected future cost: a higher initial wage increases the worker's reference wage in the subsequent renegotiation, which negatively influences effort and the value of the employment relationship to the firm. ${ }^{20} \mathrm{~A}$ marginal increase in the initial wage lowers this expected value because if the firm subsequently wants to cut the wage then the effect of negative reciprocity is greater; if it wishes to freeze the wage then the wage paid is simply higher; and if it wants to increase the wage then the effect of positive reciprocity is lower.

Next, define the marginal effect of a wage increase on the current profit in period 0 as

$$
\Psi\left(w_{0} ; q_{0}, r_{0}, \lambda\right) \equiv y_{e}\left(q, \tilde{e}\left(w_{0}, r_{0}, \lambda\right)\right) \tilde{e}_{w}\left(w_{0}, r_{0}, \lambda\right)-1 .
$$

\footnotetext{
${ }^{20}$ While this prediction may seem obvious in the context of our model, notice that in models in which the worker's effort also depends on the absolute wage level (e.g. in the spirit of Akerlof (1982)), a higher initial wage will also generate an additional expected benefit in terms of higher effort in the future, in contrast to the result established in Lemma 1.
} 
So long as $w_{0} \neq r_{0}$ the necessary first-order condition that characterises the solution to the firm's problem in (10) implies

$$
\Psi\left(w_{0} ; q_{0}, r_{0}, \lambda\right)-\delta\left|\Phi\left(w_{0}, \lambda\right)\right|=0
$$

The optimal hiring wage will be set to balance the inter-temporal tradeoff between the net marginal value in the initial period of a higher wage with the expected discounted marginal cost that stems from adaptation to this wage in the subsequent period.

As we note in the proof of the following theorem, for this condition to be also sufficient to characterise a maximum, it is required that the firm's value function $J_{0}\left(r_{0}, q_{0}\right)$ is strictly concave in $w_{0}$. This is not straightforward to prove since the sign of the derivative of $\Phi\left(w_{0}, \lambda\right)$ with respect to $w_{0}$ remains undetermined: $\Phi_{w_{0}} \lessgtr 0$ (see Appendix for details). ${ }^{21}$ Nevertheless, note that the concavity of the instantaneous profit function established in Theorem 2 implies that $J_{0}\left(r_{0}, q_{0}\right)$ will also be concave if the firm is sufficiently impatient. Hence we assume:

D3. The firm's discount factor $\delta$ is such that $\Psi_{w}\left(w_{0} ; q_{0}, r_{0}, \lambda\right)+\delta \Phi_{w_{0}}\left(w_{0}, \lambda\right)<0 .{ }^{22}$

Let $\hat{q}^{l}\left(r_{0}, \lambda, \delta\right)$ and $\hat{q}^{u}\left(r_{0}, \lambda, \delta\right)$ be the productivity thresholds defining the optimal hiring wage, respectively characterised by the value of $q_{0}$ such that

$$
\begin{aligned}
& \lim _{w \rightarrow r^{-}} \Psi\left(w ; q_{0}, r_{0}, \lambda\right)-\delta|\Phi(w, \lambda)|=0 ; \text { and } \\
& \lim _{w \rightarrow r^{+}} \Psi\left(w ; q_{0}, r_{0}, \lambda\right)-\delta|\Phi(w, \lambda)|=0 ;
\end{aligned}
$$

and let $\underline{\hat{q}}\left(r_{0}, \lambda, \delta\right)$ be the firm's reservation productivity that governs hiring, implicitly defined by $J_{0}\left(r_{0}, q_{0}\right)=0$. In a similar vein to our approach when considering a single employment period, we can derive the optimal hiring wage of a forward-looking firm, the properties of which are presented in the following theorem.

\footnotetext{
${ }^{21}$ This technicality was also an issue for the characterisation of the optimal wage policy in the model of Elsby (2009), who considered an infinite-horizon environment. However, note that while Elsby (2009) had to resort to numerical simulations to prove concavity, since we are interested in the analytical characterisation of the optimal employment contract we will impose a simplifying assumption on the firm's discount factor instead.

${ }^{22}$ If $\Phi_{w_{0}} \leq 0$, D3 holds for any $\delta \geq 0$. If $\Phi_{w_{0}}>0$, D3 implies that the firm is impatient enough so that the absolute value of the 'current direct effect' of a change in the wage on marginal profit, $\Psi_{w}$, is larger than the discounted 'expected future indirect effect' that results from the initial wage becoming the reference wage, $\Phi_{w_{0}}$. Note that this condition is on second-order effects of paying a higher initial wage.
} 
Theorem 3. The optimal hiring wage $\hat{w}\left(r_{0}, q_{0}, \lambda, \delta\right)$ is given by

$$
\hat{w}\left(r_{0}, q_{0}, \lambda, \delta\right)= \begin{cases}\hat{w}\left(r_{0}, q_{0}, \lambda, \delta\right)^{+} & \text {if } q_{0}>\hat{q}^{u}\left(r_{0}, \lambda, \delta\right) \\ r_{0} & \text { if } \hat{q}^{l}\left(r_{0}, \lambda, \delta\right) \leq q_{0} \leq \hat{q}^{u}\left(r_{0}, \lambda, \delta\right) \\ \hat{w}\left(r_{0}, q_{0}, \lambda, \delta\right)^{-} & \text {if } q_{0}<\hat{q}^{l}\left(r_{0}, \lambda, \delta\right),\end{cases}
$$

where $\hat{w}\left(r_{0}, q_{0}, \lambda, \delta\right)^{+(-)}$is implicitly defined by (12). Moreover:

a) $\hat{w}_{q}\left(r_{0}, q_{0}, \lambda, \delta\right)>0$ for all $q_{0} \in\left[\underline{\hat{q}}\left(r_{0}, \lambda, \delta\right), \infty\right) \backslash\left[\hat{q}^{l}\left(r_{0}, \lambda, \delta\right), \hat{q}^{u}\left(r_{0}, \lambda, \delta\right)\right]$; and

b) $w_{r}\left(r_{0}, q_{0}, \lambda, \delta\right)>0$ for all $q_{0} \in\left[\underline{\hat{q}}\left(r_{0}, \lambda, \delta\right), \infty\right)$.

\section{Model implications: downward wage rigidity and wage compression}

Since a forward-looking firm perceives an additional marginal cost of raising the current wage (as we established in Lemma 1), it will have an incentive to hire the worker at a lower wage, relative to that of a myopic firm in an otherwise identical employment relationship. This insight, which we will refer to as 'wage compression', was first analysed by Elsby (2009), who attributes the incentive to compress the wage entirely to a firm's anticipation of future downward wage rigidities. ${ }^{23}$ Our model identifies that it is the worker's adaptation and re-normalisation of effort - and not downward wage rigidity per se - that is the main driver of wage compression. This is formally established by the following corollary.

Corollary 1. For any $\lambda \geq 1$, a forward-looking firm will set a lower initial wage than a myopic firm:

$$
\hat{w}\left(r_{0}, q_{0}, \lambda, \delta\right) \leq \tilde{w}\left(r_{0}, q_{0}, \lambda\right)
$$

with a strict inequality whenever $w_{0} \neq r_{0}$.

Referring to the optimality condition in (12), a myopic firm only considers the current net marginal value of a higher initial wage, while a forward-looking firm also considers the expected discounted marginal cost of an increase in the hiring wage, which is positive for

\footnotetext{
${ }^{23}$ Also note that a similar wage compression effect is present in the DSGE model of Benigno and Ricci (2011) in which, however, downward wage rigidity is imposed as a purely exogenous constraint on the household's optimisation problem (see the discussion at p.1444-1446).
} 
all workers including those that are not loss averse, since

$$
\left|\Phi\left(w_{0}, 1\right)\right|=\left|\int_{\underline{q}\left(w_{0}, 1\right)}^{\infty} y_{e} \tilde{e}_{r}\left(\tilde{w}_{1}, w_{0}, 1\right) \mathrm{d} F\right|>0 .
$$

This is due to reference wage adaptation and the dynamic re-normalisation of effort: a higher initial wage that is positively reciprocated in the first employment period would translate into a higher reference wage in the subsequent period, which in turn would reduce, in expectation, the worker's extent of reciprocity in the future - reciprocity in our model is a temporary phenomenon. As such, even in the absence of downward wage rigidity, a forward-looking firm has an incentive to compress the hiring wage.

Nevertheless, does the expectation of downward wage rigidity with a worker who is loss averse reinforce or temper a firm's wage compression incentive? The answer to this question is particularly important in understanding whether the expectation of downward wage rigidity (for instance, of workers hired during recessionary episodes) would also imply a more compressed wage growth throughout the employment relationship. To provide an answer we need to analyse the effect of loss aversion $\lambda$ on the optimal hiring wage $\hat{w}_{0} \cdot{ }^{24}$ In any period, if the firm wants to pay below the reference wage then for a more loss averse worker it has a stronger incentive to reduce the gap between the unfair wage paid and the reference wage, to attenuate the stronger effect of negative reciprocity (as we established in Section 2). In the initial employment period where the reference wage is exogenous, this puts upward pressure on the hiring wage. We call this the current direct effect of loss aversion, denoted by $\Psi_{\lambda}>0$. However, due to reference wage adaptation in the subsequent employment period: on one hand i) a greater extent of loss aversion puts downward pressure on the hiring wage, since by setting a lower wage - that will translate into a lower reference wage - the firm can reduce the magnitude of the expected negative reciprocity; but on the other hand ii) since the firm will also be less willing to retain a worker who exhibits a stronger incidence of negative reciprocity (i.e., a more loss averse worker), the probability of the firm having to enact a wage cut is also lower, partially offsetting the greater expected cost of doing so. ${ }^{25}$ We define these as the expected indirect

\footnotetext{
${ }^{24}$ Our analysis concerns the hiring wage since we consider a simple two-period environment. If we were to extend the time horizon, the results derived hereafter would in fact apply to any subsequent wage payment preceding the last employment period.

${ }^{25}$ This latter effect was established in Theorem 2. As such, our model predicts that in the presence of
} 
effects of loss aversion, given by ${ }^{26}$

$$
\Phi_{\lambda}=\int_{\underline{q}}^{q^{l}} \underbrace{\left[y_{e e} \tilde{e}_{\lambda} \tilde{e}_{r}+y_{e} \tilde{e}_{r \lambda}\right]}_{i)<0} \mathrm{~d} F \underbrace{-\underline{q}_{\lambda} y_{e} \tilde{e}_{r} f\left(\underline{q} \mid q_{0}\right)}_{i i)>0} \lesseqgtr 0 .
$$

The relative importance of these effects determines the overall incidence of loss aversion on the optimal wage contract.

Corollary 2. The effect of $\lambda$ on the hiring wage depends on the following conditions:

a) if $\Phi_{\lambda}<0$ and $q_{0} \geq \hat{q}^{l}\left(r_{0}, \lambda, \delta\right)$, then $\hat{w}_{\lambda}\left(r_{0}, q_{0}, \lambda, \delta\right)<0$;

b) if $\Phi_{\lambda}<0$ and $q_{0}<\hat{q}^{l}\left(r_{0}, \lambda, \delta\right)$, then $\hat{w}_{\lambda}\left(r_{0}, q_{0}, \lambda, \delta\right)<0 \Leftrightarrow \Psi_{\lambda}<\delta\left|\Phi_{\lambda}\right|$;

c) if $\Phi_{\lambda} \geq 0$, then $\hat{w}_{\lambda}\left(r_{0}, q_{0}, \lambda, \delta\right) \geq 0$.

Corollary 2 establishes that the effect of $\lambda$ on the optimal hiring wage $\hat{w}_{0}$ is ambiguous, which is a very natural conclusion given the effects at play in our model. Suppose, for the initial part of this discussion, that the probability of being in a situation to enact costly wage cuts in the future is sufficiently high so that $\Phi_{\lambda}<0$ (i.e. the lay-off reservation productivity $\underline{q}\left(w_{0}, \lambda\right)$ does not increase too much with $\lambda$, which implies that effect ii) identified above is sufficiently small). Now consider a worker that is hired at a relatively high match productivity $q_{0} \geq \hat{q}^{l}\left(r_{0}, \lambda, \delta\right)$, i.e. case $a$ ) (hence $\hat{w}_{0} \geq r_{0}$ so $\Psi_{\lambda}=0$, i.e., there is no current direct effect of loss aversion). In this particular case the expectation of stronger negative reciprocity and downward wage rigidity would unambiguously lead to wage compression, since the firm optimally sets a lower wage to keep the worker's wage entitlement low and reduce the extent of the expected negative reciprocity if $\tilde{w}_{1}<\tilde{w}_{0}$ in the subsequent employment period.

Next consider a worker that is hired at a relatively low match productivity $q_{0}<$ $\hat{q}^{l}\left(r_{0}, \lambda, \delta\right)$, i.e., case $b$ ) (hence $\hat{w}_{0}<r_{0}$ and $\Psi_{\lambda}>0$ ). In this case, a higher $\lambda$ would loss averse workers, there will be both downward wage rigidity and layoffs in periods in which productivity declines. This implies that if we were to simulate the model the full extent of downward wage rigidity may not be observed in the distribution of wage changes following a large negative shock even if it is a salient feature of the employment contract: firms that are critically constrained by downward wage rigidity will lay off the least productive workers. This is consistent with the recent work by Kurmann and McEntarfer (2017) who find that in the U.S. during the Great Recession wage freezes have been less popular, which they attribute not to a lack of downward wage rigidity but to the least productive workers being laid off, and to the most productive workers receiving wage cuts.

${ }^{26}$ For a detailed derivation of this expression, see the proof of Corollary 2 in the Appendix. 
lead to wage compression only if the firm's incentive to set a higher wage to attenuate negative reciprocity in period 0 is dominated by the incentive to set a lower wage to keep the worker's reference wage low, and to reduce their negative reciprocity response in the event of a future (unfair) wage cut in period 1. However, notice that these conclusions are subject to presuming that $\Phi_{\lambda}<0$. If, as in case $\left.c\right), \Phi_{\lambda} \geq 0$, there is an additional marginal consideration that partially offsets the wage compression incentive: a greater probability of layoff following a large negative shock implies that the probability of the firm having to incur the cost of negative reciprocity in period 1 is also lower. As such we conclude that the expectation of downward wage rigidity does not necessarily lead to wage compression. ${ }^{27}$ Our model highlights that the incentive for wage compression is driven by a worker's reference wage adaptation and dynamic re-normalisation of effort; and that wage rigidity may either strengthen or dampen this incentive.

\section{Model implications: loss aversion and hiring}

We conclude our investigation of asymmetric reference-dependent reciprocity and wage rigidity on the nature of the employment contract by considering the effect of loss aversion $\lambda$ on the firm's hiring reservation productivity $\underline{\hat{q}}\left(r_{0}, \lambda, \delta\right)$. There are two channels through which a higher degree of loss aversion could influence the value of the employment relationship to the firm. First, there is a direct negative effect on effort in each period as negative reciprocity is stronger for a more loss averse worker. Second, there is an indirect effect that comes from our analysis related to Corollary 2: if the hiring wage is increasing in $\lambda$ this provides a compounding negative effect on expected future effort and a higher labour cost, which lowers profit; whilst if the initial wage is decreasing in $\lambda$-i.e. wage compression - there is a partially offsetting positive effect on expected future effort and a

\footnotetext{
${ }^{27}$ It may be argued that in a long-term employment relationship the initial effect of negative reciprocity will not be so important that firms will always compress hiring wages. However, this statement is not necessarily true for two reasons. First, the expected future indirect effects of loss aversion are discounted, so it is still possible that the current direct effect dominates. Second, in our model the expectation of downward wage rigidity also reduces the expected duration of the employment relationship (by increasing the firm's future lay-off reservation productivity), since firms would optimally layoff workers rather than implementing costly wage cuts. This latter effect (i.e. effect ii) of equation (13)) reduces the range of negative shocks over which a firm would experience negative reciprocity due to a wage cut, and therefore reduces the related costs of doing so. Note that the models of Elsby (2009) and Benigno and Ricci (2011), which consider an infinite horizon, do not feature a lay-off reservation productivity that is endogenous to optimal wage setting and reciprocity. This is why downward wage rigidity unambiguously implies wage compression in their models.
} 
lower labour cost, which increases profit. Nevertheless, we can show that if a firm is considering contracting with a more loss averse worker the reservation productivity determining hiring unambiguously increases, independently of how the hiring wage adjusts.

Proposition 1. The firm's reservation productivity for hiring is increasing in $\lambda$ :

$$
\frac{\mathrm{d} \underline{\hat{q}}\left(r_{0}, \lambda, \delta\right)}{\mathrm{d} \lambda}>0
$$

The mechanism behind the neutrality of this result to changes in the hiring wage lies in the firm's optimal wage setting: since the initial wage is set to balance the expected direct/indirect effects of loss aversion on output (effort) and labour cost (wage) at the margins to satisfy the first-order condition in (12), a higher degree of loss aversion negatively affects profit only through the stronger negative reciprocity response of the worker whenever $\tilde{w}_{t}<r_{t}$. Thus, independently of whether wage rigidity reinforces or tempers the incentive to compress hiring wages, the anticipation of stronger negative reciprocity and the expectation of downward wage rigidity unambiguously reduce a firm's incentive to hire.

This prediction is consistent with the empirical evidence reported in Kurmann and McEntarfer (2017), who find that firms that are more constrained by downward wage rigidity employ on average higher productivity employees. Moreover, this result has implications for understanding the effects of wage rigidity on job creation. In the literature concerned with labour market fluctuations, much attention has been devoted to the effect of wage rigidity in the wages paid to newly hired workers on firms' job creation incentives (see for instance Pissarides (2009), the discussion in Elsby et al. (2015) and references therein). In contrast, Proposition 1 establishes that it is the anticipated negative reciprocity and the expected wage rigidity of incumbents that reduces a firm's incentive to hire, independently of the rigidity/flexibility of the hiring wage. As such, our analysis suggests that incorporating our model into a richer macroeconomic framework could potentially enhance the understanding of the effects of anticipated wage rigidities of existing/incumbent workers on job creation and unemployment. 


\section{Model implications: discussion}

The in-depth and transparent modelling approach we have taken in this paper allowed us to rigorously analyse the relative importance of loss aversion, asymmetric reciprocity and expected downward wage rigidity for a forward-looking firm's incentive to compress wages and hire in a dynamic environment. While there are a number of other models in the literature that feature downward wage rigidity (e.g. Elsby (2009), Holden and Wulfsberg (2009), Eliaz and Spiegler (2014), Benjamin (2015), Kaur (2018)) the theoretical predictions that we derived in this section are unique to our approach and constitute the main contribution of our paper. For instance, our analysis of the effects of expected downward wage rigidity for wage compression would not be possible using a reduced-form approach such as in Eliaz and Spiegler (2014) or Kaur (2018). Moreover, our in-depth analysis of the inter-temporal tradeoffs faced by a forward-looking firm enabled us to conclude that the expectation of downward wage rigidity does not necessarily lead to wage compression (as other reduced-form models such as Elsby (2009) would suggest). On the other hand, in models such as Holden and Wulfsberg (2009) — which do not directly consider workers' effort - the key mechanism behind downward wage rigidity is that firms do not cut wages because otherwise their workers will rather stay unemployed (or be employed somewhere else). In our model firms do not cut wages to avoid damaging morale and incurring the costs of negative reciprocity. Both explanations are plausible, but they are also undoubtedly different and will lead to different results if one were to analyse their implications further, as we have done.

\section{Conclusion}

In this paper we have advanced a microeconomic theory of asymmetric reciprocity and optimal wage setting based on contractual incompleteness, fairness, and reference dependence and loss aversion in the evaluation of wage contracts by workers. This approach allows us to rigorously formalise several aspects of wage and effort dynamics, and to study their implications for the nature of the employment contract within a plausible and tractable model. By establishing a clear link between assumptions and conclusions, our theory provides novel 
insights to explain the observed asymmetry and dynamics of workers' reciprocity, and to identify the sources of downward wage rigidity, wage compression and hiring incentives.

We formally characterise a worker's effort response to wage changes to be reference dependent, where positive and negative reciprocity are defined as relative deviations from normal effort, and loss aversion is identified as the psychological foundation for the stronger intensity of negative reciprocity. In addition, we show that the reference-dependent nature of reciprocity, combined with adaptation, leads to a dynamic 're-normalisation' of effort throughout the employment relationship: reciprocity is a temporary phenomenon. This prediction is consistent with the recent experimental findings of Sliwka and Werner (2017) and with other evidence documented in the field (e.g. Mas (2006) and Gneezy and List $(2006))$.

By subsequently analysing the implications of our theory of asymmetric referencedependent reciprocity for optimal wage setting in a two-period environment, we establish that downward wage rigidity is an inherent feature of the employment contract; and we identify an asymmetric adjustment cost around the past wage to be a necessary ingredient for models of dynamic downward wage rigidity. In our model this mechanism is generated by the worker's adaptation of the reference wage and the relatively large cost of negative reciprocity in response to wage cuts (that stems from loss aversion). As such we think of our model as a general and plausible micro-foundation for downward wage rigidity in a dynamic environment.

When analysing the consequences of these wage and effort dynamics for the optimal employment contract, we draw new conclusions about their implications for a forwardlooking firm's wage compression incentive (Elsby, 2009), and for the expected value of the employment relationship, which influences hiring decisions. We find that the primary behavioural mechanism that generates wage compression is the anticipation of the worker's re-normalisation of effort due to adaptation, even absent downward wage rigidity. In a model in which layoffs are endogenous to optimal wage setting, the expectation of downward wage rigidity may not necessarily lead to wage compression. Nevertheless, independently of how the hiring wage adjusts, the anticipation of stronger negative reciprocity and the expectation of downward wage rigidity unambiguously reduces the expected value 
of the employment relationship, implying that a firm that expects to be constrained by downward wage rigidity in the future will hire less on average.

The framework developed in this paper lends itself as a tractable benchmark model for the analysis of reference-dependent reciprocity, adaptation and wage rigidity, and their effect on wage setting and hiring behaviour. Two possible extensions are as follows. First, it will be interesting to analyse the model's predictions under different specifications of a worker's reference wage. We chose the past wage as the only determinant of an incumbent worker's reference wage as it is the most corroborated hypothesis in the empirical literature. Nevertheless, there are other plausible determinants of the reference wage that may differ depending on whether the worker is a new hire or an incumbent. For instance a newly hired worker's reference wage could be influenced by the state of the labour market (as in the efficiency wage tradition, e.g. Akerlof (1982) and Summers (1988)), the most recent wage contract paid in the previous employment relationship (as considered in Koenig et al. (2016)), or the wage of incumbent workers employed by the same firm (as the "equal treatment" hypothesis of Snell and Thomas (2010) would suggest). On the other hand an existing/incumbent worker's reference wage might be influenced by the wage of their peers outside the firm (as in Keynes (1936), Bhaskar (1990) or Driscoll and Holden (2004)), by expectations (as in Eliaz and Spiegler (2014) and Macera and te Velde (2018)) or by the firm's ability to pay (as in Danthine and Kurmann (2007)). We take a simple approach in this paper that nevertheless generates predictions in line with stylised facts, but a very interesting direction for future research is to gain further understanding of what influences the reference wage in a labour market setting, and determine whether or not adaptation is symmetric for wage increases and reductions. Like every model based on reference dependence, predictions are sensitive to the choice of reference point and investigating if, and how, our conclusions might change is the natural next step. Second, we believe that exploring the insights of the model within a richer macroeconomic framework can shed new light on the effects of expected wage rigidity in long-term employment relationships for job creation and wage dynamics (see Fongoni (2018b) for a first step into this direction). As discussed in Elsby et al. (2015) this aspect is not yet settled in the theory of labour market fluctuations, and has drawn particular attention in light of recent cross-country experiences 
following the Great Recession (Elsby et al., 2016). Therefore, a promising line of future research lies in developing and combining these two extensions.

\section{Appendix: Additional Material}

\section{Deriving the worker's participation constraint}

We want to derive an expression for the worker's reservation wage defining their participation constraint. In our model this is the wage below which a worker will optimally turn down a job offer and stay unemployed in period 0 , or quit the job and move to unemployment in period 1 . Denote by $W_{t}\left(w_{t}, r_{t}\right)$ the value of the employment relationship to the worker in period $t$ and normalise the value of being unemployed to zero. The worker's reservation wage in each period can be defined as: $\underline{w}\left(r_{t}, q_{t}\right)=\left\{0, w_{t}: W_{t}\left(w_{t}, r_{t}\right)=0\right\}$.

By noting that the worker's decision to turn down a job offer would be made after observing the optimal wage contract set by the firm, and considering that $r_{1}=\tilde{w}_{0}$ due to adaptation, we can express the value of the two-period employment relationship to the worker as

$$
\begin{aligned}
& W_{0}\left(\tilde{w}\left(r_{0}, q_{0}\right), r_{0}\right)=u_{0}\left(\tilde{e}\left(\tilde{w}\left(r_{0}, q_{0}\right), r_{0}, \lambda\right) ; \tilde{w}\left(r_{0}, q_{0}\right), r_{0}\right) \\
& \quad+\gamma \int_{\underline{q}\left(\tilde{w}\left(r_{0}, q_{0}\right), \lambda\right)}^{\infty} W_{1}\left(\tilde{w}\left(\tilde{w}\left(r_{0}, q_{0}\right), q_{1}\right), \tilde{w}\left(r_{0}, q_{0}\right)\right) d F\left(q_{1} \mid q_{0}\right),
\end{aligned}
$$

where $\gamma$ is the worker's discount factor and the optimal wage has been denoted here by $\tilde{w}\left(r_{t}, q_{t}\right)$ (i.e. excluding the other time-invariant functional arguments to ease notation). This expression can then be used to derive the reservation wage $\underline{w}\left(r_{t}, q_{t}\right)$ for each $t=\{0,1\}$, the effect of which is to add an additional threshold to the model.

However, note that the reservation wage in each period will be a function of exogenous variables only, i.e. the initial reference wage $r_{0}$ and the initial match productivity $q_{0}$. Hence it would be straightforward to impose a condition on these such that the worker's participation constraint is never binding. While doing so will not affect the results presented in this paper, the modelling of this condition might be relevant in a richer framework in which the worker's initial reference wage is endogenous, and, in particular, dependant on 
the state of the labour market.

\section{Appendix: Proofs}

Proof of Theorem 1. We suppose Assumptions W1-W3 hold throughout. We seek a level of effort such that $-d^{\prime}(e)+n(w \mid r)=0$. Note that under W2 $-d^{\prime}(e)+n(w \mid r)$ is continuous and strictly decreasing in $e$, and takes negative values when $e$ is large enough. As such, so long as $-d^{\prime}(e)+n(w \mid r)>0$ when $e=0$ there will be a single value of $e>0$ satisfying the first-order condition. A sufficient condition for $-d^{\prime}(0)+n(w \mid r)>0$ for all wages is $\left|d^{\prime}(0)\right|>\lambda \eta v(r)$, which we assume to be the case throughout. Thus, optimal effort is given by the inverse function $\tilde{e}(w, r, \lambda)=d^{\prime-1}(n(w \mid r))$. Since $d^{\prime}$ is a continuous function and $n(w \mid r)$ varies continuously in $w$ and $r, \tilde{e}(w, r, \lambda)$ will be a continuous function of $w$ and $r$, but it will not be continuously differentiable everywhere as, recalling its definition from (4), $n(w \mid r)$ has a kink at $w=r$. For $w \neq r$ we can apply the inverse function theorem to give

$$
\tilde{e}_{w}(w, r, \lambda)= \begin{cases}\frac{\eta v^{\prime}(w)}{d^{\prime \prime}(e)} & \text { if } w>r \\ \frac{\lambda \eta v^{\prime}(w)}{d^{\prime \prime}(e)} & \text { if } w<r\end{cases}
$$

so $\tilde{e}_{w}(w, r, \lambda)>0$ for all finite $w \neq r$, and $\lim _{w \rightarrow \infty} \tilde{e}_{w}=0$ since we assume $\lim _{w \rightarrow \infty} v^{\prime}(w)=$ 0. It then follows that

$$
\tilde{e}_{w w}(w, r, \lambda)= \begin{cases}\frac{\eta v^{\prime \prime}(w)}{d^{\prime \prime}(e)} & \text { if } w>r \\ \frac{\lambda \eta v^{\prime \prime}(w)}{d^{\prime \prime}(e)} & \text { if } w<r\end{cases}
$$

so $\tilde{e}_{w w}(w, r, \lambda)<0$ for all $w \neq r$.

By appealing to the definition of normal effort when $w=r$, we can deduce that

$$
\begin{aligned}
\lim _{w \rightarrow r^{-}} \tilde{e}_{w}(w, r, \lambda)^{-}=-\lim _{w \rightarrow r^{-}} \frac{\lambda \eta v^{\prime}(w)}{d^{\prime \prime}\left(\tilde{e}(w, r, \lambda)^{-}\right)} & =-\frac{\lambda \eta v^{\prime}(r)}{d^{\prime \prime}\left(\tilde{e}_{n}\right)} \\
& =-\lambda \lim _{w \rightarrow r^{+}} \frac{\eta v^{\prime}(w)}{d^{\prime \prime}\left(\tilde{e}(w, r)^{+}\right)}=\lambda \lim _{w \rightarrow r^{+}} \tilde{e}_{w}(w, r)^{+} .
\end{aligned}
$$

Hence the effort function kinks to a flatter slope as the wage increases. Note that this, combined with the deduction that $\tilde{e}_{w w}<0$ for all $w \neq r$, implies $\tilde{e}_{w}$ is everywhere decreasing in $w$, i.e. the effort function is concave.

The inverse function theorem and the definition of $n(w \mid r)$ can then be used to deduce 
the remainder of the claims:

$$
\tilde{e}_{r}(w, r, \lambda)= \begin{cases}-\frac{\eta v^{\prime}(r)}{d^{\prime \prime}(e)} & \text { if } w>r \\ -\frac{\lambda \eta v^{\prime}(r)}{d^{\prime \prime}(e)} & \text { if } w<r\end{cases}
$$

so $\tilde{e}_{r}(w, r, \lambda)<0$ for all $w \neq r$,

$$
\tilde{e}_{\lambda}(w, r, \lambda)= \begin{cases}0 & \text { if } w>r \\ \frac{\eta[v(w)-v(r)]}{d^{\prime \prime}(e)}<0 & \text { if } w<r\end{cases}
$$

and so for $w<r$

$$
\tilde{e}_{w \lambda}(w, r, \lambda)=\frac{\eta v^{\prime}(w)}{d^{\prime \prime}(e)}>0
$$

Proof of Theorem 2. Throughout the proof we assume the worker's productivity and reference wage are such that $q \geq \underline{q}(r, \lambda)$ so the firm will be profitable if it hires the worker, and consider the properties of the threshold productivity at the end. We proceed by stating some preliminaries, then considering the productivity thresholds, then demonstrating the nature of the optimal wage setting rule. First we consider the sufficiency of the first-order condition in identifying a maximum. For $w \neq r$ concavity of profit requires $y_{e e}\left[\tilde{e}_{w}\right]^{2}+y_{e} \tilde{e}_{w w}<0$. This follows from our assumptions and the conclusion of Theorem 1 that for $w \neq r \tilde{e}_{w w}<0$. To ensure concavity over the entire domain we need to ensure that at $w=r$ the marginal profit reduces, which follows again from the conclusions of Theorem 1 that imply $\lim _{w \rightarrow r^{-}} \tilde{e}_{w}(w, r, \lambda)^{-} \geq \lim _{w \rightarrow r^{+}} \tilde{e}_{w}(w, r, \lambda)^{+}$, where the inequality is strict if $\lambda>1$. Note also that profit will obtain a maximum as the fact that $\lim _{w \rightarrow \infty} \tilde{e}_{w}=0$ implies marginal profit will be negative for large enough $w$.

Preliminaries: To ease notational burden denote the left-hand side of the first-order condition (7), i.e. the marginal profit, by $\Psi(w ; q, r, \lambda)$. First, note that under Assumption F1 and the results of Theorem 1 , for $w \neq r$ we have that $\Psi_{q}(w ; q, r, \lambda)=y_{q e} \tilde{e}_{w}>0$; $\Psi_{r}(w ; q, r, \lambda)=y_{e e} \tilde{e}_{r} \tilde{e}_{w}+y_{e} \tilde{e}_{w r} \geq 0$ (after noting that $\left.\tilde{e}_{w r}=0\right)$; and $\Psi_{w}(w ; q, r, \lambda)=$ $y_{e e}\left[\tilde{e}_{w}\right]^{2}+y_{e} \tilde{e}_{w w}<0$. In addition, $\Psi_{\lambda}=y_{e e} \tilde{e}_{\lambda} \tilde{e}_{w}+y_{e} \tilde{e}_{w \lambda}$ so $\Psi_{\lambda}>0$ if $w<r$ and $\Psi_{\lambda}=0$ if $w>r$. 
Productivity thresholds: The threshold $q^{l}(r, \lambda)$ identifies the critical match productivity below which the firm would want to set the wage below the reference wage, and $q^{u}(r)$ is the match productivity above which the firm would want to compensate the worker more than the reference wage. The former is the value of $q$ below which profit is decreasing just below the reference wage (so concavity of profit and the fact that $\Psi_{q}>0$ imply that for all $q$ below this, profit will be maximised when $w<r)$; the latter is the value of $q$ above which profit is increasing just above the reference wage (so concavity of profit and $\Psi_{q}>0$ imply that for all $q$ exceeding this, profit will be maximised when $w>r)$. Since $\Psi(w, 0, r, \lambda)<0$ when $w>0$ and $\Psi_{q}>0$ there will be a unique value of each productivity threshold.

We now want to establish some properties of the thresholds. Implicit differentiation (noting that the limit changes) allows us to deduce that

$$
\begin{aligned}
q_{r}^{l}(r, \lambda) & =-\lim _{w \rightarrow r^{-}} \frac{\Psi_{w}(w ; q, r, \lambda)+\Psi_{r}(w ; q, r, \lambda)}{\Psi_{q}(w ; q, r, \lambda)} \text { and } \\
q^{u \prime}(r) & =-\lim _{w \rightarrow r^{+}} \frac{\Psi_{w}(w ; q, r, \lambda)+\Psi_{r}(w ; q, r, \lambda)}{\Psi_{q}(w ; q, r, \lambda)} .
\end{aligned}
$$

Now,

$$
\begin{aligned}
\Psi_{w}(w ; q, r, \lambda)+\Psi_{r}(w ; q, r, \lambda) & =y_{e e}\left[\tilde{e}_{w}\right]^{2}+y_{e} \tilde{e}_{w w}+y_{e e} \tilde{e}_{r} \tilde{e}_{w} \\
& =y_{e e} \tilde{e}_{w}\left[\tilde{e}_{w}+\tilde{e}_{r}\right]+y_{e} \tilde{e}_{w w}
\end{aligned}
$$

As $w \rightarrow r^{ \pm}$we can infer that $\tilde{e}_{w}(w, r, \lambda)^{ \pm}+\tilde{e}_{r}(w, r, \lambda)^{ \pm} \rightarrow 0$ (refer to the expressions of these objects in the proof of Theorem 1), implying $\lim _{w \rightarrow r^{ \pm}} \Psi_{w}(w ; q, r, \lambda)+\Psi_{r}(w ; q, r, \lambda)=$ $y_{e} \tilde{e}_{w w}^{ \pm}<0$. This allows us to conclude that $q_{r}^{l}(r, \lambda)>0$ and $q^{u \prime}(r)>0$.

Turning next to investigate how the lower threshold depends on the degree of loss aversion, implicit differentiation gives

$$
\begin{aligned}
q_{\lambda}^{l}(r, \lambda) & =-\lim _{w \rightarrow r^{-}} \frac{\Psi_{\lambda}(w, q, r, \lambda)}{\Psi_{q}(w, q, r, \lambda)} \\
& =-\frac{y_{e e} \lim _{w \rightarrow r^{-}} \tilde{e}_{\lambda}(w, r, \lambda)^{-} \lim _{w \rightarrow r^{-}} \tilde{e}_{w}(w, r, \lambda)^{-}+y_{e} \lim _{w \rightarrow r^{-}} \tilde{e}_{w \lambda}(w, r, \lambda)^{-}}{\lim _{w \rightarrow r^{-}} \Psi_{q}(w ; q, r, \lambda)}<0
\end{aligned}
$$

since we deduced in Theorem 1 that $\tilde{e}_{\lambda}^{-}<0$ and $\tilde{e}_{w \lambda}^{-}>0$.

The consideration of $\lim _{w \rightarrow r^{-}} \Psi(w ; q, r \lambda)-\lim _{w \rightarrow r^{+}} \Psi(w ; q, r, \lambda)$ in the preliminaries 
allows us to conclude that when $\lambda=1$ these two objects are equal. This, combined with the observation that $\lim _{w \rightarrow r^{-}} \tilde{e}(w, r, \lambda)^{-}=\tilde{e}_{n}=\lim _{w \rightarrow r^{+}} \tilde{e}(w, r)$ (from Theorem 1) permits the conclusion that $q^{l}(r, 1)=q^{u}(r)$. This, along with the fact that $q_{\lambda}^{l}(r, \lambda)<0$, implies $q^{l}(r, \lambda)<q^{u}(r)$ for all $\lambda>1$.

Optimal wage setting: We now turn to the optimal wage setting rule, which depends on the match productivity in relation to the productivity thresholds.

If $q \in\left[q(r, \lambda), q^{l}(r, \lambda)\right)$ then the definition of $q^{l}(r, \lambda)$ and fact that $\Psi_{q}>0$ can be used to deduce that $\lim _{w \rightarrow r^{-}} \Psi(w, q, r, \lambda)<0$; since $\Psi(w ; q, r, \lambda)$ is everywhere decreasing in $w$, the same is true for all $w \geq r$. As such, the optimising wage must satisfy $w<r$ and will therefore be the solution to

$$
y_{e}\left(q, \tilde{e}(w, r, \lambda)^{-}\right) \tilde{e}_{w}(w, r, \lambda)^{-}-1 \leq 0
$$

with equality if $w>\underset{\sim}{w}(r, \lambda)$ (recall from the proof of Theorem 1 that this is the wage below which effort takes the boundary value of zero). To account for the fact that the firm may pay the 'lowest feasible wage' for a range of match productivity, let $\breve{q}(r, \lambda)=\max \{0, q$ : $\Psi(\underset{w}{w}(r, \lambda) ; q, r, \lambda)=0\}$ (at $\breve{q}(r, \lambda)$ the firm would want to pay $\underset{w}{w}(r, \lambda)$ and since $\Psi_{q}>0$ the same will be true for all $0 \leq q<\breve{q}(r, \lambda))$. For all $\breve{q}(r, \lambda)<q<q^{l}(r, \lambda)$ the optimal wage is given by the displayed first-order condition holding with equality, which is denoted by $\tilde{w}(r, q, \lambda)^{-}$. Implicit differentiation and our deductions in the preliminaries reveal

$$
\begin{aligned}
& \tilde{w}_{q}(r, q, \lambda)^{-}=-\frac{\Psi_{q}}{\Psi_{w}}>0, \\
& \tilde{w}_{r}(r, q, \lambda)^{-}=-\frac{\Psi_{r}}{\Psi_{w}} \geq 0, \text { and } \\
& \tilde{w}_{\lambda}(r, q, \lambda)^{-}=-\frac{\Psi_{\lambda}}{\Psi_{w}}>0 .
\end{aligned}
$$

If $q \in\left(q^{u}(r), \infty\right)$ then the definition of $q^{u}(r)$ and the fact that $\Psi_{q}>0$ can be used to deduce that $\lim _{w \rightarrow r^{+}} \Psi(w, q, r, \lambda)>0$; since $\Psi(w ; q, r, \lambda)$ is everywhere decreasing in $w$ the same is true for all $w \leq r$ and, as such, the optimising wage must exceed $r$ and will therefore satisfy

$$
y_{e}\left(q, \tilde{e}(w, r)^{+}\right) \tilde{e}_{w}(w, r)^{+}-1=0
$$


Letting $\tilde{w}(q, r)^{+}$denote the solution (which is independent of $\lambda$ ), implicit differentiation gives

$$
\begin{aligned}
& \tilde{w}_{q}(r, q)^{+}>0 \text { and } \\
& \tilde{w}_{r}(r, q)^{+} \geq 0 .
\end{aligned}
$$

If $q \in\left[q^{l}(r, \lambda), q^{u}(r)\right]$ then the fact that $\Psi_{q}>0$ can be used to deduce that $\lim _{w \rightarrow r^{-}} \Psi(w, q, r, \lambda) \geq$ 0 and $\lim _{w \rightarrow r^{+}} \Psi(w, q, r, \lambda) \leq 0$. That $\Psi_{w}<0$ for all $w \neq r$ then implies $\Psi(w ; q, r, \lambda)>0$ for all $w<r$ and $\Psi(w ; q, r, \lambda)<0$ for all $w>r$, implying profit is maximised if and only if $w=r$.

Finally, if $q<\underline{q}(r, \lambda)$ then then the employment relationship ends. Implicit differentiation of the zero profit condition defining the reservation productivity allows us to deduce that

$$
\begin{aligned}
\underline{q}_{r}(r, \lambda) & =-\frac{y_{e}\left[\tilde{e}_{r}+\tilde{e}_{w} \tilde{w}_{r}\right]-\tilde{w}_{r}}{y_{q}+y_{e} \tilde{e}_{w} \tilde{w}_{q}-\tilde{w}_{q}} \\
& =-\frac{\tilde{w}_{r}\left[y_{e} \tilde{e}_{w}-1\right]+y_{e} \tilde{e}_{r}}{\tilde{w}_{q}\left[y_{e} \tilde{e}_{w}-1\right]+y_{q}}>0
\end{aligned}
$$

since $y_{e} \tilde{e}_{w}-1=0$ from the first-order condition, $y_{q}, y_{e}>0$ by Assumption F1 and we found in Theorem 1 that $\tilde{e}_{r}<0$. In addition,

$$
\begin{aligned}
\underline{q}_{\lambda}(r, \lambda) & =-\frac{y_{e}\left[\tilde{e}_{\lambda}+\tilde{e}_{w} \tilde{w}_{\lambda}\right]-\tilde{w}_{\lambda}}{y_{q}+y_{e} \tilde{e}_{w} \tilde{w}_{q}-\tilde{w}_{q}} \\
& =-\frac{\tilde{w}_{\lambda}\left[y_{e} \tilde{e}_{w}-1\right]+y_{e} \tilde{e}_{\lambda}}{\tilde{w}_{q}\left[y_{e} \tilde{e}_{w}-1\right]+y_{q}} .
\end{aligned}
$$

Again $y_{e} \tilde{e}_{w}-1=0$ and $y_{q}, y_{e}>0$, and we found in Theorem 1 that when $w>r \tilde{e}$ is independent of $\lambda$, but when $w<r, \tilde{e}_{\lambda}<0$. As such, if $\tilde{w}(r, \underline{q}(r, \lambda), \lambda)>r$ then $\underline{q}_{\lambda}(r, \lambda)=0$ but if $\tilde{w}(r, \underline{q}(r, \lambda), \lambda)<r, \underline{q}_{\lambda}(r, \lambda)>0$.

Proof of Lemma 1. Recall that $J_{1}\left(w_{0}, q_{1}\right)^{-;=;+}$represents the continuation value of the employment relationship when $w_{1}<w_{0} ; w_{1}=w_{0} ; w_{1}>w_{0}$, in which effort is given by $\tilde{e}\left(w_{1}, w_{0}, \lambda\right)^{-} ; \tilde{e}^{n} ; \tilde{e}\left(w_{1}, w_{0}\right)^{+}$. The marginal effect of a wage increase in period 0 , which becomes the worker's reference wage in period 1, on the expected continuation value of the 
employment relationship to the firm is given by (where $\mathrm{d} F \equiv \mathrm{d} F\left(q_{1} \mid q_{0}\right)$ ):

$$
\begin{gathered}
\frac{\partial}{\partial r_{1}} \int_{\underline{q}\left(w_{0}, \lambda\right)}^{\infty} J_{1}\left(w_{0}, q_{1}\right) \mathrm{d} F=\int_{\underline{q}\left(w_{0}, \lambda\right)}^{q^{l}\left(w_{0}, \lambda\right)} J_{1, r_{1}}\left(w_{0}, q_{1}\right)^{-} \mathrm{d} F-\underline{q}_{r} J_{1}\left(w_{0}, \underline{q}\right) f\left(\underline{q} \mid q_{0}\right) \\
+q_{r}^{l} \lim _{\epsilon \rightarrow 0} J_{1}\left(w_{0}, q^{l}-\epsilon\right)^{-} f\left(q^{l} \mid q_{0}\right)+\int_{q^{l}\left(w_{0}, \lambda\right)}^{q^{u}\left(w_{0}\right)} J_{1, r_{1}}\left(w_{0}, q_{1}\right)^{=} \mathrm{d} F \\
-q_{r}^{l} \lim _{\epsilon \rightarrow 0} J_{1}\left(w_{0}, q^{l}\right)^{=} f\left(q^{l} \mid q_{0}\right)+q^{u \prime} \lim _{\epsilon \rightarrow 0} J_{1}\left(w_{0}, q^{u}\right)^{=} f\left(q^{u} \mid q_{0}\right) \\
\quad+\int_{q^{u}\left(w_{0}\right)}^{\infty} J_{1, r_{1}}\left(w_{0}, q_{1}\right)^{+} \mathrm{d} F-q^{u \prime} \lim _{\epsilon \rightarrow 0} J_{1}\left(w_{0}, q^{u}+\epsilon\right)^{-} f\left(q^{u} \mid q_{0}\right) .
\end{gathered}
$$

By definition, $J_{1}\left(w_{0}, \underline{q}\right)=0$, and the continuity of the optimal effort function and wage imply $\lim _{\epsilon \rightarrow 0} J_{1}\left(w_{0}, q^{l}-\epsilon\right)^{-}=J_{1}\left(w_{0}, q^{l}\right)=$ and $\lim _{\epsilon \rightarrow 0} J_{1}\left(w_{0}, q^{u}+\epsilon\right)^{+}=J_{1}\left(w_{0}, q^{u}\right)=$. Hence, the derivatives with respect to the integral limits $q^{l}$ and $q^{u}$ cancel each other out, which yields:

$$
\begin{array}{r}
\int_{\underline{q}\left(w_{0}, \lambda\right)}^{\infty} J_{1, r_{1}}\left(w_{0}, q_{1}\right) \mathrm{d} F=\int_{\underline{q}\left(w_{0}, \lambda\right)}^{q^{l}\left(w_{0}, \lambda\right)} J_{1, r_{1}}\left(w_{0}, q_{1}\right)^{-} \mathrm{d} F+\int_{q^{l}\left(w_{0}, \lambda\right)}^{q^{u}\left(w_{0}\right)} J_{1, r_{1}}\left(w_{0}, q_{1}\right)^{=} \mathrm{d} F \\
+\int_{q^{u}\left(w_{0}\right)}^{\infty} J_{1, r_{1}}\left(w_{0}, q_{1}\right)^{+} \mathrm{d} F
\end{array}
$$

Now, for $q_{1} \in\left[\underline{q}\left(w_{0}, \lambda\right), \infty\right) \backslash\left[q^{l}\left(w_{0}, \lambda\right), q^{u}\left(w_{0}\right)\right]$ (i.e. where $\left.w \neq r\right)$ :

$$
J_{1, r_{1}}\left(r_{1}, q_{1}\right)^{ \pm}=y_{e} \tilde{e}_{r}^{ \pm}<0
$$

since we deduced in Theorem 1 that $\tilde{e}_{r}<0$. For $q_{1} \in\left[q^{l}\left(w_{0}, \lambda\right), q^{u}\left(w_{0}\right)\right]$ (i.e. where $w=r$ and optimal effort is $\left.\tilde{e}^{n}\right)$ :

$$
J_{1, r_{1}}\left(r_{1}, q_{1}\right)^{=}=\pi_{w}=-1<0
$$

As such,

$$
\int_{\underline{q}\left(w_{0}, \lambda\right)}^{\infty} J_{1, r_{1}}\left(w_{0}, q_{1}\right) \mathrm{d} F=\int_{\underline{q}}^{q^{l}} y_{e} \tilde{e}_{r}^{-} \mathrm{d} F-\int_{q^{l}}^{q^{u}} 1 \mathrm{~d} F+\int_{q^{u}}^{\infty} y_{e} \tilde{e}_{r}^{+} \mathrm{d} F<0
$$

which corresponds to our definition of $\Phi\left(w_{0}, \lambda\right)$.

Proof of Theorem 3. The proof is qualitatively similar to the proof of Theorem 2, so the 
details are largely omitted. Let us, however, dwell on the condition that

$$
\Psi_{w}+\delta \Phi_{w_{0}}<0
$$

establishing concavity of the value function in $w_{0}$. We know from the proof of Theorem 2 that $\Psi\left(w ; q_{0}, r_{0}, \lambda\right)$ is decreasing in $w$, as $\Psi_{w}<0$ for $w \neq r$ and at $w=r$ there is a jump down. Recalling the expression for $\Phi\left(w_{0}, \lambda\right)$ in (14) and recognising that both the integrand (except in the case of $q_{1} \in\left[q^{l}\left(w_{0}, \lambda\right), q^{u}\left(w_{0}\right)\right]$ ) and the limits of integration depend on $w_{0}$, we deduce that

$$
\begin{aligned}
\Phi_{w_{0}}=\int_{\underline{q}}^{q^{l}} \frac{\mathrm{d}}{\mathrm{d} r}\left\{y_{e} \tilde{e}_{r}\right\} \mathrm{d} F-\underline{q}_{r} y_{e} \tilde{e}_{r} f\left(\underline{q} \mid q_{0}\right)+q_{r}^{l} y_{e} \lim _{w_{1} \rightarrow w_{0}^{-}} \tilde{e}_{r}\left(w_{1}, w_{0}, \lambda\right) f\left(q^{l} \mid q_{0}\right) \\
+q_{r}^{l} s^{\prime} f\left(q^{l} \mid q_{0}\right)-q^{u \prime} f\left(q^{u} \mid q_{0}\right) \\
\quad-q^{u \prime} y_{e} \lim _{w_{1} \rightarrow w_{0}^{+}} \tilde{e}_{r}\left(w_{1}, w_{0}, \lambda\right) f\left(q^{u} \mid q_{0}\right)+\int_{q^{u}}^{\infty} \frac{\mathrm{d}}{\mathrm{d} r}\left\{y_{e} \tilde{e}_{r}\right\} \mathrm{d} F .
\end{aligned}
$$

Now, from the expressions for $\tilde{e}_{w}$ and $\tilde{e}_{r}$ in the proof of Theorem 1 it follows that

$$
\lim _{w_{1} \rightarrow w_{0}^{-(+)}} \tilde{e}_{r}\left(w_{1}, w_{0}, \lambda\right)=-\lim _{w_{1} \rightarrow w_{0}^{-(+)}} \tilde{e}_{w}\left(w_{1}, w_{0}, \lambda\right) .
$$

Moreover, when $w \neq r$ the first-order condition holds with equality, which implies that $y_{e} \tilde{e}_{w}-1=0$. These statements together give us $y_{e} \lim _{w_{1} \rightarrow w_{0}^{-(+)}} \tilde{e}_{r}\left(w_{1}, w_{0}, \lambda\right)+1=0$, which allows several terms to cancel in the above expression. Noting that $\frac{\mathrm{d}}{\mathrm{d} r}\left\{y_{e} \tilde{e}_{r}\right\}=$ $y_{e} \tilde{e}_{r r}+y_{e e}\left[\tilde{e}_{r}\right]^{2}$ then allows us to conclude that

$$
\Phi_{w_{0}}=\int_{\underline{q}}^{q^{l}}\left[y_{e} \tilde{e}_{r r}+y_{e e}\left[\tilde{e}_{r}\right]^{2}\right] \mathrm{d} F+\int_{q^{u}}^{\infty}\left[y_{e} \tilde{e}_{r r}+y_{e e}\left[\tilde{e}_{r}\right]^{2}\right] \mathrm{d} F-\underline{q}_{r} y_{e} \tilde{e}_{r} f\left(\underline{q} \mid q_{0}\right) .
$$

Hence, after noticing that $\tilde{e}_{r r}=-\tilde{e}_{w w}$ and collecting this term as the common factor, we 
can rewrite the expression $\Psi_{w}+\delta \Phi_{w_{0}}$ as:

$$
\begin{aligned}
& \tilde{e}_{w w}\left\{y_{e}-\delta\left[\int_{\underline{q}}^{q^{l}} y_{e} \mathrm{~d} F+\int_{q^{u}}^{\infty} y_{e} \mathrm{~d} F\right]\right\} \\
&+y_{e e}\left[\tilde{e}_{w}\right]^{2}+\delta\left[\int_{\underline{q}}^{q^{l}} y_{e e}\left[\tilde{e}_{r}\right]^{2} \mathrm{~d} F+\int_{q^{u}}^{\infty} y_{e e}\left[\tilde{e}_{r}\right]^{2} \mathrm{~d} F\right] \\
&-\delta \underline{q}_{r} y_{e} \tilde{e}_{r} f\left(\underline{q} \mid q_{0}\right) .
\end{aligned}
$$

We know from Theorem 1 that $\tilde{e}_{r}<0$ and $\tilde{e}_{w w}<0$, and from Theorem 2 that $\underline{q}_{r}>0$. This implies that: the first line in the expression above is negative only if the term in curly brackets is positive; the second line is negative; and the last line is positive.

The term in curly brackets captures the difference between the 'current' and the 'expected discounted future' marginal effect of effort on output (i.e. the effect of a greater reciprocity today, due to a higher wage, versus lower reciprocity in the future, due to a higher reference wage); while the last line captures the marginal increase in the firm's lay-off reservation productivity, which reduces the support of the distribution over which the firm will employ a worker with a higher reference wage in the subsequent employment period. As such we can deduce that if the current effect of reciprocity dominates the expected discounted future effect of reciprocity on the firm's value of the employment relationship, and if the firm's lay-off reservation productivity does not increase too much, then expression (15) will be negative, as required.

Nevertheless, under Assumption D3 this deduction always holds and the proof of the nature of the optimal wage follows the same steps as the proof of Theorem 2 where $\Psi$ is replaced with $\Psi+\delta \Phi$.

Proof of Corollary 1. The proof relies on investigation of the first-order condition of the two optimisation problems, noting from Lemma 1 that $\Phi\left(w_{0}, \lambda\right)<0$. First we show that $\hat{q}^{l}(r, \lambda, \delta)>\tilde{q}^{l}(r, \lambda)$. Suppose, by contradiction, that $\hat{q}^{l} \leq \tilde{q}^{l}$, then the fact that $\Psi_{q}>0$ (see the preliminaries in the proof of Theorem 2) implies

$$
0 \equiv \lim _{w \rightarrow r^{-}} \Psi\left(w ; \tilde{q}^{l}, r, \lambda\right) \geq \lim _{w \rightarrow r^{-}} \Psi\left(w, \hat{q}^{l}, r, \lambda\right)
$$


but then since $\Phi(w, \lambda)<0$ we have that

$$
\lim _{w \rightarrow r^{-}} \Psi\left(w, \hat{q}^{l}, r, \lambda\right)>\lim _{w \rightarrow r^{-}} \Psi\left(w, \hat{q}^{l}, r, \lambda\right)+\delta \Phi(w, \lambda) \equiv 0
$$

yielding a contradiction. That $\hat{q}^{u}(r, \lambda, \delta)>\tilde{q}^{u}(r)$ is similarly proved.

We now want to compare $\hat{w}(r, q, \lambda, \delta)^{-;+}$with $\tilde{w}(r, q, \lambda)^{-;+}$where both functions are defined. We demonstrate that $\hat{w}(r, q, \lambda, \delta)^{-}<\tilde{w}(r, q, \lambda)^{-}$for all $q<\tilde{q}^{l}(r, \lambda)$. Suppose, by contradiction, that $\hat{w}^{-} \geq \tilde{w}^{-}$. Then the fact that $\Psi_{w}<0$ (see the preliminaries in the proof of Theorem 2) implies

$$
0 \equiv \Psi\left(\tilde{w}^{-} ; q, r, \lambda\right) \geq \Psi\left(\hat{w}^{-} ; q, r, \lambda\right)
$$

but then $\Phi\left(w_{0}, \lambda\right)<0$ implies

$$
\Psi\left(\hat{w}^{-} ; q, r, \lambda\right)>\Psi\left(\hat{w}^{-} ; q, r, \lambda\right)+\delta \Phi(r, \lambda) \equiv 0
$$

yielding a contradiction. The proof that $\hat{w}(r, q, \lambda, \delta)^{+}<\tilde{w}(r, q, \lambda)^{+}$for all $q>\hat{q}^{u}(r, \lambda, \delta)$ is similar and so omitted.

Proof of Corollary 2. Consider how the optimal wage changes with the degree of loss aversion. Implicit differentiation of the wage setting rule gives

$$
\hat{w}_{\lambda}=-\frac{\Psi_{\lambda}+\delta \Phi_{\lambda}}{\Psi_{w}+\delta \Phi_{w}} .
$$

By Assumption D3 the denominator is negative, and we know from the preliminaries in the proof of Theorem 2 that $\Psi_{\lambda}=0$ if $w \geq r$ and $\Psi_{\lambda}>0$ if $w<r$. Recalling the definition of $\Phi\left(w_{0}, \lambda\right)$ in (14) and noting that $\pi_{w}$ and $q^{u}$ are independent of $\lambda$, we deduce that

$$
\begin{aligned}
\Phi_{\lambda}=\int_{\underline{q}}^{q^{l}} \frac{\mathrm{d}}{\mathrm{d} \lambda}\left\{y_{e} \tilde{e}_{r}\right\} & \mathrm{d} F-\underline{q}_{\lambda} y_{e} \tilde{e}_{r} f\left(\underline{q} \mid q_{0}\right) \\
& +q_{\lambda}^{l} y_{e} \lim _{w_{1} \rightarrow w_{0}^{-}} \tilde{e}_{r}\left(w_{1}, w_{0}, \lambda\right) f\left(q^{l} \mid q_{0}\right)+q_{\lambda}^{l} f\left(q^{l} \mid q_{0}\right)+\int_{q^{u}}^{\infty} \frac{\mathrm{d}}{\mathrm{d} \lambda}\left\{y_{e} \tilde{e}_{r}\right\} \mathrm{d} F .
\end{aligned}
$$

Now, the derivatives with respect to the integral limits cancel out since as we deduced 
previously $y_{e} \lim _{w_{1} \rightarrow w_{0}^{-}} \tilde{e}_{r}\left(w_{1}, w_{0}, \lambda\right)+1=0$. Moreover, $\frac{\mathrm{d}}{\mathrm{d} \lambda}\left\{y_{e} \tilde{e}_{r}\right\}=y_{e e} \tilde{e}_{\lambda} \tilde{e}_{r}+y_{e} \tilde{e}_{r \lambda}$ which, according to our deductions in Theorem 1, is equal to zero for wages exceeding the reference wage. As such,

$$
\Phi_{\lambda}=\int_{\underline{q}}^{q^{l}}\left[y_{e e} \tilde{e}_{\lambda} \tilde{e}_{r}+y_{e} \tilde{e}_{r \lambda}\right] \mathrm{d} F-\underline{q}_{\lambda} y_{e} \tilde{e}_{r} f\left(\underline{q} \mid q_{0}\right) .
$$

In Theorem 1 we concluded that $\tilde{e}_{\lambda}, \tilde{e}_{r}, \tilde{e}_{r \lambda}<0$ and we know from Theorem 2 that $\underline{q}_{\lambda}>0$. As such, the sign of $\Phi_{\lambda}$ remains undetermined, so we cannot sign $\Psi_{\lambda}+\delta \Phi_{\lambda}$, but rather conclude that $w_{\lambda} \gtreqless 0 \Leftrightarrow \Psi_{\lambda}+\delta \Phi_{\lambda} \gtreqless 0$. Note that if the layoff reservation productivity does not increase too much, i.e. $\underline{q}_{\lambda} y_{e} \tilde{e}_{r} f\left(\underline{q} \mid q_{0}\right)$ is sufficiently small, then $\Phi_{\lambda}<0$.

Proof of Proposition 1. The reservation productivity governing hiring behaviour in the initial contract is characterised by

$$
\underline{\hat{q}}\left(r_{0}, \lambda, \delta\right)=\max \left\{0, q_{0}: \pi\left(\hat{w}\left(r_{0}, q_{0}, \lambda, \delta\right), r_{0}, q_{0}, \lambda\right)+\delta \mathbb{E}\left[J_{1}\left(\hat{w}\left(r_{0}, q_{0}, \lambda, \delta\right), q_{1}\right)\right]=0\right\} .
$$

Implicit differentiation reveals

$$
\begin{aligned}
\frac{\mathrm{d} \underline{\hat{q}}}{\mathrm{~d} \lambda} & =-\frac{y_{e}\left[\tilde{e}_{w} \hat{w}_{\lambda}+\tilde{e}_{\lambda}\right]-\hat{w}_{\lambda}+\delta \frac{\mathrm{d} \mathbb{E}_{0}\left[J_{1}\left(\hat{w}\left(r_{0}, q_{0}, \lambda, \delta\right), q_{1}\right)\right]}{\mathrm{d} \lambda}}{y_{q}+y_{e} \tilde{e}_{w} \hat{w}_{q_{0}}-\hat{w}_{q_{0}}+\delta \frac{\mathrm{d} \mathbb{E}_{0}\left[J_{1}\left(\hat{w}\left(r_{0}, q_{0}, \lambda, \delta\right), q_{1}\right)\right]}{\mathrm{d} q_{0}}} \\
& =-\frac{y_{e} \tilde{e}_{\lambda}+\hat{w}_{\lambda}\left[y_{e} \tilde{e}_{w}-1\right]+\delta \frac{\mathrm{d \mathbb {E } _ { 0 } [ J _ { 1 } ( \hat { w } ( r _ { 0 } , q _ { 0 } , \lambda , \delta ) , q _ { 1 } ) ]}}{\mathrm{d} \lambda}}{y_{q}+\hat{w}_{q_{0}}\left[y_{e} \tilde{e}_{w}-1\right]+\delta \frac{\mathrm{d} \mathbb{E}_{0}\left[J_{1}\left(\hat{w}\left(r_{0}, q_{0}, \lambda, \delta\right), q_{1}\right)\right]}{\mathrm{d} q_{0}}}
\end{aligned}
$$

Letting $\pi^{-;=;+}$be the profit function when $w_{1}<w_{0} ; w_{1}=w_{0} ; w_{1}>w_{0}$, in which effort is given by $\tilde{e}\left(w_{1}, w_{0}, \lambda\right)^{-} ; \tilde{e}^{n} ; \tilde{e}\left(w_{1}, w_{0}\right)^{+}$, we have

$$
\begin{aligned}
\frac{\mathrm{d} \mathbb{E}_{0}\left[J_{1}\right]}{\mathrm{d} \lambda} & =\int_{\underline{q}}^{q^{l}} \frac{\mathrm{d} \pi^{-}}{\mathrm{d} \lambda} \mathrm{d} F-\left.\frac{\mathrm{d} \underline{q}}{\mathrm{~d} \lambda} \pi^{-}\right|_{q=\underline{q}} f\left(\underline{q} \mid q_{0}\right)+\left.\frac{\mathrm{d} q^{l}}{\mathrm{~d} \lambda} \pi^{-}\right|_{q=q^{l}} f\left(q^{l} \mid q_{0}\right) \\
& +\int_{q^{l}}^{q^{u}} \frac{\mathrm{d} \pi^{=}}{\mathrm{d} \lambda} \mathrm{d} F+\left.\frac{\mathrm{d} q^{u}}{\mathrm{~d} \lambda} \pi^{=}\right|_{q=q^{u}} f\left(q^{u} \mid q_{0}\right)-\left.\frac{\mathrm{d} q^{l}}{\mathrm{~d} \lambda} \pi^{=}\right|_{q=q^{l}} f\left(q^{l} \mid q_{0}\right) \\
& +\int_{q^{u}}^{\infty} \frac{\mathrm{d} \pi^{+}}{\mathrm{d} \lambda} \mathrm{d} F-\left.\frac{\mathrm{d} q^{u}}{\mathrm{~d} \lambda} \pi^{+}\right|_{q=q^{u}} f\left(q^{u} \mid q_{0}\right) .
\end{aligned}
$$

Noting that $\left.\pi^{-}\right|_{q=q} \equiv 0$, and that since $\left.\pi^{-,+}\right|_{q=q^{l}}=\pi^{=}$and $\left.\pi^{-,+}\right|_{q=q^{u}}=\pi^{=}$, the other effects on the limits of integration cancel out, this reduces to

$$
\frac{\mathrm{dE}_{0}\left[J_{1}\right]}{\mathrm{d} \lambda}=\int_{\underline{q}}^{q^{l}} \frac{\mathrm{d} \pi^{-}}{\mathrm{d} \lambda} \mathrm{d} F+\int_{q^{l}}^{q^{u}} \frac{\mathrm{d} \pi^{=}}{\mathrm{d} \lambda} \mathrm{d} F+\int_{q^{u}}^{\infty} \frac{\mathrm{d} \pi^{+}}{\mathrm{d} \lambda} \mathrm{d} F .
$$


Now,

$$
\begin{aligned}
\frac{\mathrm{d} \pi^{-;+}}{\mathrm{d} \lambda} & =y_{e} \tilde{e}_{\lambda}+y_{e} \tilde{e}_{w} \tilde{w}_{\lambda}+y_{e} \tilde{e}_{r} \hat{w}_{\lambda}-\tilde{w}_{\lambda} \\
& =y_{e} \tilde{e}_{\lambda}+y_{e} \tilde{e}_{r} \hat{w}_{\lambda}+\tilde{w}_{\lambda}\left[y_{e} \tilde{e}_{w}-1\right] \\
& =y_{e}\left[\tilde{e}_{\lambda}+\tilde{e}_{r} \hat{w}_{\lambda}\right]
\end{aligned}
$$

since $y_{e} \tilde{e}_{w}-1=0$ by the first-order condition. However, within the range of rigidity we have

$$
\frac{\mathrm{d} \pi^{=}}{\mathrm{d} \lambda}=-\hat{w}_{\lambda}
$$

Note that $\hat{w}_{\lambda}$ doesn't depend on $q_{1}$ and $\tilde{e}_{\lambda}=0$ when the wage exceeds the reference wage.

Then, recalling the expression for $\Phi\left(w_{0}, \lambda\right)$ in (14), we have that

$$
\begin{aligned}
\frac{\mathrm{d} \mathbb{E}_{0}\left[J_{1}\right]}{\mathrm{d} \lambda} & =\int_{\underline{q}}^{q^{l}} y_{e}\left[\tilde{e}_{\lambda}+\tilde{e}_{r} \hat{w}_{\lambda}\right] \mathrm{d} F-\int_{q^{l}}^{q^{u}} \hat{w}_{\lambda} \mathrm{d} F+\int_{q^{u}}^{\infty} y_{e} \tilde{e}_{r} \hat{w}_{\lambda} \mathrm{d} F \\
& =\int_{\underline{q}}^{q^{l}} y_{e} \tilde{e}_{\lambda} \mathrm{d} F+\hat{w}_{\lambda} \int_{\underline{q}}^{q^{l}} y_{e} \tilde{e}_{r} \mathrm{~d} F-\hat{w}_{\lambda} \int_{q^{l}}^{q^{u}} 1 \mathrm{~d} F+\hat{w}_{\lambda} \int_{q^{u}}^{\infty} y_{e} \tilde{e}_{r} \mathrm{~d} F \\
& =\hat{w}_{\lambda} \Phi+\int_{\underline{q}}^{q^{l}} y_{e} \tilde{e}_{\lambda} \mathrm{d} F .
\end{aligned}
$$

This allows us to write the expression for the numerator in (16) as

$$
\begin{aligned}
y_{e} \tilde{e}_{\lambda}+\hat{w}_{\lambda}\left[y_{e} \tilde{e}_{w}-1\right]+\delta \frac{\mathrm{d} \mathbb{E}_{0}\left[J_{1}\left(\hat{w}\left(r_{0}, q_{0}, \lambda, \delta\right), q_{1}\right)\right]}{\mathrm{d} \lambda} & =\hat{w}_{\lambda}\left[y_{e} \tilde{e}_{w}-1+\delta \Phi\right]+y_{e} \tilde{e}_{\lambda}+\delta \int_{\underline{q}}^{q^{l}} y_{e} \tilde{e}_{\lambda} \mathrm{d} F \\
& =y_{e} \tilde{e}_{\lambda}+\delta \int_{\underline{q}}^{q^{l}} y_{e} \tilde{e}_{\lambda} \mathrm{d} F
\end{aligned}
$$

since the first-order condition for the initial wage implies $y_{e} \tilde{e}_{w}-1+\delta \Phi=0$.

Similar deductions allow us to conclude that $\frac{\mathrm{d} \mathbb{E}_{0}\left[J_{1}\right]}{\mathrm{d} q_{0}}=\hat{w}_{q_{0}} \Phi$, and therefore to write the expression for the denominator in (16) as

$$
\begin{aligned}
y_{q}+\hat{w}_{q_{0}}\left[y_{e} \tilde{e}_{w}-1\right]+\delta \frac{\mathrm{d} \mathbb{E}_{0}\left[J_{1}\left(\hat{w}\left(r_{0}, q_{0}, \lambda, \delta\right), q_{1}\right)\right]}{\mathrm{d} q_{0}} & =\hat{w}_{q_{0}}\left[y_{e} \tilde{e}_{w}-1+\delta \Phi\right]+y_{q} \\
& =y_{q} .
\end{aligned}
$$


As such,

$$
\frac{\mathrm{d} \underline{\hat{q}}}{\mathrm{~d} \lambda}=-\frac{y_{e} \tilde{e}_{\lambda}+\delta \int_{\underline{q}}^{q^{l}} y_{e} \tilde{e}_{\lambda} \mathrm{d} F}{y_{q}}>0
$$

since we know from Theorem 1 that when $w<r$, then $\tilde{e}_{\lambda}<0$.

\section{References}

Abdellaoui, M., H. Bleichrodt, and C. Paraschiv (2007). Loss Aversion Under Prospect Theory: A Parameter-Free Measurement. Management Science 53(10), 1659-1674.

Agell, J. and H. Bennmarker (2007). Wage Incentives and Wage Rigidity: A Representative View From Within. Labour Economics 14(3), 347-369.

Ahrens, S., I. Pirschel, and D. J. Snower (2015). Path-Dependent Wage Responsiveness. Kiel Working Papers No. 1977.

Akerlof, G. A. (1982). Labor Contracts as Partial Gift Exchange. Quarterly Journal of Economics 97(4), 543-569.

Akerlof, G. A. and J. L. Yellen (1990). The Fair Wage-Effort Hypothesis and Unemployment. Quarterly Journal of Economics CV(2), 255-283.

Altmann, S., A. Falk, A. Grunewald, and D. Huffman (2014). Contractual Incompleteness, Unemployment, and Labour Market Segmentation. Review of Economic Studies 81(October 2013), 30-56.

Babecký, J., P. Du Caju, T. Kosma, M. Lawless, J. Messina, and T. Rõõm (2010, dec). Downward Nominal and Real Wage Rigidity: Survey Evidence from European Firms. Scandinavian Journal of Economics 112(4), 884-910.

Bartling, B. and K. M. Schmidt (2015). Reference Points, Social Norms, and Fairness in Contract Renegotiations. Journal of the European Economic Association 13(1), 98-129.

Baucells, M. and R. K. Sarin (2010). Predicting Utility Under Satiation and Habit Formation. Management Science 56(2), 286-301. 
Benigno, P. and L. A. Ricci (2011). The Inflation-Output Trade-Off with Downward Wage Rigidities. American Economic Review 101 (June), 1436-1466.

Benjamin, D. J. (2015). A Theory of Fairness in Labour Markets. Japanese Economic Review 66(2), 182-225.

Bewley, T. F. (1999). Why Wages Don't Fall During a Recession. London: Harvard University Press.

Bewley, T. F. (2007). Fairness, Reciprocity, and Wage Rigidity. In P. Diamond and H. Vartiainen (Eds.), Behavioural Economics and Its Applications. Princeton University Press.

Bhaskar, V. (1990). Wage Relativities and the Natural Range of Unemployment. Economic Journal 100(400), 60-66.

Campbell, C. M. and K. S. Kamlani (1997). The Reasons for Wage Rigidity: Evidence From Survey of Firms. Quarterly Journal of Economics 112, 759-789.

Chemin, M. and A. Kurmann (2014). Do Workers Feel Entitled to High Wages? Evidence from a Long-Term Field Experiment. Working Paper, 1-44.

Clark, A. E., D. Masclet, and M. C. Villeval (2010). Effort and Comparison Income: Experimental and Survey Evidence. ILR Review 63(3), 407-426.

Cohn, A., E. Fehr, and L. Goette (2014). Fair Wages and Effort Provision: Combining Evidence from a Choice Experiment and a Field Experiment. Management Science.

Cox, J. C., D. Friedman, and S. Gjerstad (2007). A tractable model of reciprocity and fairness. Games and Economic Behavior 59, 17-45.

Danthine, J.-P. and A. Kurmann (2006). Efficiency Wages Revisited: The Internal Reference Perspective. Economics Letters 90(2), 278 - 284.

Danthine, J.-P. and A. Kurmann (2007, dec). The Macroeconomic Consequences of Reciprocity in Labor Relations. Scandinavian Journal of Economics 109(4), 857-881. 
Danthine, J.-P. and A. Kurmann (2010, oct). The Business Cycle Implications of Reciprocity in Labor Relations. Journal of Monetary Economics 57(7), 837-850.

Dickens, W. T., L. Goette, L. Erica, S. Holden, J. Messina, E. Mark, J. Turunen, and M. E. Ward (2007). How Wages Change : Micro Evidence from the International Wage Flexibility Project. Journal of Economic Perspectives 21(2), 195-214.

Driscoll, J. C. and S. Holden (2004, apr). Fairness and Inflation Persistence. Journal of the European Economic Association 2(2-3), 240-251.

Dufwenberg, M. and G. Kirchsteiger (2000). Reciprocity and wage undercutting. European Economic Review 44(4), 1069 - 1078.

Dufwenberg, M. and G. Kirchsteiger (2004, may). A Theory of Sequential Reciprocity. Games and Economic Behavior 47(2), 268-298.

Eliaz, K. and R. Spiegler (2014). Reference Dependence and Labor-Market Fluctuations. NBER Macroeconomics Annual 28, 159-200.

Elsby, M. W. L. (2009). Evaluating the Economic Significance of Downward Nominal Wage Rigidity. Journal of Monetary Economics 56(2), 154-169.

Elsby, M. W. L., R. Michaels, and D. Ratner (2015). The Beveridge Curve: A Survey. Journal of Economic Literature 53(3), 571-630.

Elsby, M. W. L., D. Shin, and G. Solon (2016). Wage Adjustments in the Great Recession and Other Downturns: Evidence from the United States and Great Britain. Jornal of Labor Economics 34, 249-291.

Fehr, E. and L. Goette (2005, may). Robustness and real consequences of nominal wage rigidity. Journal of Monetary Economics 52(4), 779-804.

Fehr, E., L. Goette, and C. Zehnder (2009, sep). A Behavioral Account of the Labor Market: The Role of Fairness Concerns. Annual Review of Economics 1(1), 355-384.

Fehr, E., O. Hart, and C. Zehnder (2011). Contracts as Reference Points-Experimental Evidence. American Economic Review 101 (April), 493-525. 
Fehr, E., O. Hart, and C. Zehnder (2014). How Do Informal Agreements and Revision Shape Contractual Reference Points? Journal of the European Economic Association: forthcoming.

Fehr, E. and K. M. Schmidt (1999). A Theory of Fairness, Competition, and Cooperation. Quarterly Journal of Economics 114(3), 817-868.

Fongoni, M. (2018a). A Theoretical Note on: Asymmetries in Intensity and Persistence of Reciprocity in Labour Markets. University of Strathclyde Working Papers No. 1815.

Fongoni, M. (2018b). Workers' Reciprocity and the (Ir)Relevance of Wage Cyclicality for the Volatility of Job Creation. University of Strathclyde Working Papers No. 1809.

Gächter, S. and C. Thöni (2010). Social Comparison and Performance: Experimental Evidence on the Fair Wage-effort Hypothesis. Journal of Economic Behavior $\&$ Organization $76(3), 531-543$.

Gneezy, U. and J. A. List (2006). Putting Behavioral Economics to Work: Testing For Gift Exchange in Labor Markets Using Field Experiments. Econometrica 74(5), 1365-1384.

Hart, O. and J. Moore (2008). Contracts as Reference Points. Quarterly Journal of Economics CXXIII(February), 1-48.

Herweg, F. and K. M. Schmidt (2012). Loss Aversion and Ex Post Inefficient Renegotiation. University of Munich, Working Paper.

Herz, H. and D. Taubinsky (2018). What Makes a Price Fair? An Experimental Study of Transaction Experience and Endogenous Fairness Views. Journal of the European Economic Association 16(2), 316-352.

Holden, S. and F. Wulfsberg (2009). How Strong is the Macroeconomic Case for Downward Real Wage Rigidity? Journal of Monetary Economics 56, 605-615.

Holden, S. and F. Wulfsberg (2014). Wage Rigidity, Inflation, and Institutions. Scandinavian Journal of Economics 116(2), 539-569.

Kahneman, D., J. L. Knetsch, and R. H. Thaler (1986). Fairness as a Constraint on Profit Seeking: Entitlements in the Market. American Economic Review 76(4), 728-741. 
Kahneman, D. and R. H. Thaler (1991). Economic Analysis and the Psychology of Utility: Applications to Compensation Policy. The American Economic Review 81(2), 341-346.

Kahneman, D. and A. Tversky (1979). Prospect Theory: An Analysis of Decision under Risk. Econometrica 47(2), 263-292.

Kaur, S. (2018). Nominal Wage Rigidity in Village Labor Markets. American Economic Review (Forthcoming).

Keynes, J. M. (1936). The General Theory of Employment, Interest and Money. London: MacMillan and Cambridge University Press.

Koch, C. (2017). Do Reference Points Erode Fairness? Experimental Evidence on Wage Rigidity. Working Paper, 1-36.

Koenig, F., A. Manning, and B. Petrongolo (2016). Reservation Wages and the Wage Flexibility Puzzle. IZA Discussion Paper No. 9717.

Kube, S., M. A. Maréchal, and C. Puppe (2013). Do Wage Cuts Damage Work Morale? Evidence from a Natural Field Experiment. Journal of the European Economic Association 11(4), 853-870.

Kurmann, A. and E. McEntarfer (2017). Downward Wage Rigidity in the United States: New Evidence from Administrative Data. Working Paper.

Macera, R. and V. L. te Velde (2018). On the Power of Surprising versus Anticipated Gifts in the Workplace. Working Paper.

Malmendier, U., V. L. Velde, and R. Weber (2014). Rethinking Reciprocity. Annual Review of Economics 6, 849-974.

Mas, A. (2006). Pay, Reference Points, and Police Performance. Quarterly Journal of Economics CXXI(3), 783-821.

McDonald, I. M. and H. Sibly (2001). How Monetary Policy can have permanent real effects with only temporary Nominal Rigidity. Scottish Journal of Political Economy 48(5), $532-546$. 
Nickell, S. and G. Quintini (2003). Nominal Wage Rigidity and the Rate of Inflation. The Economic Journal 113(490), 762-781.

Pissarides, C. A. (2009). The Unemployment Volatility Puzzle: Is Wage Stickiness the Answer? Econometrica 77(5), 1339-1369.

Rabin, M. (1993). Incorporating Fairness into Game Theory and Economics. American Economic Review 83(5), 1281-1301.

Sliwka, D. and P. Werner (2017). Wage Increases and the Dynamics of Reciprocity. Journal of Labor Economics 35(2), 299-344.

Snell, A. and J. P. Thomas (2010). Labor Contracts, Equal Treatment, and WageUnemployment Dynamics. American Economic Journal: Macroeconomics 2(3), 98-127.

Summers, L. H. (1988). Relative Wages, Efficiency Wages, and Keynesian Unemployment. American Economic Review 78(2), 383-388.

Tversky, A. and D. Kahneman (1991). Loss Aversion in Riskless Choice: a Reference Dependent Model. Quarterly Journal of Economics 106(4), 1039-1061.

Williamson, O. E. (1985). The Economic Institutions of Capitalism: Firms, Markets, Relational Contracting. New York: The Free Press. 